\title{
Michail Peramatzis*
}

\section{Conceptions of Truth in Plato's Sophist}

https://doi.org/10.1515/agph-2020-1015

\begin{abstract}
The paper seeks to specify how, according to Plato's Sophist, true statements achieve their being about objects and their saying that 'what is about such objects is'. Drawing on the 6th definition of the sophist, I argue for a normative-teleological conception of truth in which the best condition of our soul -in its making statements or having mental states- consists in its seeking to attain the telos of truth. Further, on the basis of Plato's discussion of original and image, his distinction between correct and incorrect image, and the 7th definition, I argue that achieving the telos of truth involves preserving the original's proportions and appropriate features. The view that Plato's conception of truth takes statements or mental states to be certain types of image is not ground-breaking. The important contribution of my argument is that it offers a plausible way to understand two recalcitrant claims made by Plato: first, that falsity obtains not only in the region of incorrect images (appearances) but also within correct images (likenesses); second, that some incorrect images are based on knowledge and so could be true.
\end{abstract}

\section{Introduction}

The principal aim of this paper is exegetical. While my discussion will raise some important conceptual points, its focus will be on understanding Plato's view of truth as formulated in the Sophist. Surprisingly, I shall make only a few brief remarks about his direct comments on true and false statements (logoi) in the core section of the dialogue. His idea that a true statement says about a thing 'what is, that it is' (while a false logos fails to do so) is an intuitive and influential conception of truth and falsity. Later developments in philosophical discussions of truth, extending from Aristotle to modern views, are indebted to this conception. ${ }^{1}$ My aim, however, is to examine whether, and if so, how the Sophist could

1 See, for example, Aristotle, Metaph. Г.7, 1011b25-27; cf. Tarski 1944, 342f.; 360.

*Corresponding author: Michail Peramatzis, Philosophy Faculty, University of Oxford, Worcester College, OX1 2HB, Oxford, UK; michail.peramatzis@philosophy.ox.ac.uk 
develop further this conception by specifying how true statements achieve their being about objects and their saying that what is about such objects is.

First, I shall draw on important remarks Plato makes in the $6^{\text {th }}$ attempt at a definition of the sophist. He compares knowing the truth with bodily beauty conceived as proportion, and argues that the excellent condition of our soul, understood as its most proportionate state, is such as to aim at and hit the mark of truth. ${ }^{2}$ From these metaphorical remarks I shall derive a normative-teleological conception of truth in which the best condition of our soul - in its making statements or having mental states - consists in its seeking to attain, and achieving, the telos of truth.

Second, on the basis of Plato's discussion of original and image, his distinction between correct (eikôn: likeness) and incorrect image (phantasma: appearance), and the $7^{\text {th }}$ definition, I shall argue that achieving the goal of truth (as described in the normative-teleological conception) involves producing a sort of image which preserves the proportions and appropriate features of the original the relevant part of external reality. This idea takes up and extends the notion of proportion from the normative-teleological conception.

It should be noted that my view does not identify the distinction between likeness (correct image) and appearance (incorrect image) with that between

2 It is helpful to note that Plato's use of the terms alêtheia, alêthes, and alêthinon is not straightforward. My claims will sometimes reflect this aspect of his usage. Hence, alêthinon is normally employed for what is genuine, the original, or the real (see my discussion in Section 4.2). By contrast, alêtheia and alêthes are more difficult. There are two basic types of use: (a) the 'ontic' or 'reality' usage, which is reserved for an object or external reality; (b) the 'truth-bearer' usage which picks out the property of truth as it applies to standard truth-bearers. Plato could use (a) to indicate (what we would call) facts or states of affairs; he could also use it for a thing, object, entity, Form, or defining essence; finally, he could use it to describe an image taken as an object or a part of external reality. On the other hand, (b) could be used for a (true) statement, thought, belief, or proposition. Moreover, (b) could attach either to 'atomic' truth-bearers (such as 'Theaetetus is sitting') or to 'molecular' truth-bearers (e. g., a set of claims, a whole speech, a discussion, a body of statements constituting a theory, etc.). When alêtheia and alêthes are used for a 'true image', they may indicate an image 'out there', as it were, along the lines of (a) - e. g., a painting or a statue. Or they could imply an accurate or faithful copy of an original. In this last case Plato may be speaking of an accurate thought, conception, or even representation; or he could be referring to a true statement, proposition, etc. Given Plato's account of thought as inner dialogue, and his claim that belief is a sort of outcome or completion of that dialogue (Theaetetus 189e1-190a7; Sophist 263d6-264b5), it would not be misleading to think that, in his view, thoughts, conceptions, or even representations are propositional or quasi-propositional along the lines of usage (b) of aletheia and alêthes for standard truth-bearers. These distinctions will become clearer in what follows. For further discussion see Szaif 1998 [especially 72-182 for the 'ontic' usage (a)], Hestir 2003, 20-24, and Hestir 2016, 235-42. 
truth and falsity. Rather, I shall argue that an image is correct (and so is a likeness) in that it aims (or is a result of aiming) at the truth, the reproduction of the original's proportions and features. By contrast, an image is incorrect just in case it either does not aim at truth at all, or it aims at falsehood (or non-truth). This distinction between correct and incorrect images allows for the possibility that a likeness may be false, even if it is correct, i.e. truth-aiming. In this way, my view accommodates Plato's claim that falsity obtains not only in the region of appearances but also within likenesses (260c6-10; 264c10-d2). I shall argue that this point also explains Plato's insistence on there being appearances which are based on knowledge and so could, in some way, be true (267b7-e3). For even an incorrect image - one which aims at falsehood in the form of some type of deception - may be made knowledgeably and so involve truth.

The view that Plato's conception of truth takes statements or mental states (such as beliefs or opinions) to be certain types of image is by no means ground-breaking. The important contribution of the present argument is that it offers a plausible way to understand the two recalcitrant claims made by Plato just sketched in the previous paragraph: first, that falsity obtains not only in the region of incorrect images (appearances) but also within correct images (likenesses); second, that some incorrect images are based on knowledge and so could be true.

There is a further, more general respect in which my argument adopts a novel interpretative line. The question of how the core section of the Sophist relates to the introductory and final, 'outside' or 'frame' sections (in which Plato offers his definitions by division) is a notorious crux. The typical approach to this question is to argue that the 'frame' sections draw on the core: for without the latter we could not spell out or underpin the arguments of the former, especially the $7^{\text {th }}$ definition, which seems to be accepted as correct at the end of the dialogue. ${ }^{3} \mathrm{My}$ view agrees with this but suggests an additional, converse direction of dependence: for if my interpretation is correct, the 'frame' sections are crucial for understanding Plato's account of truth and falsity offered in the core.

3 Neither this point, nor my overall argument, depend on the additional claim that Plato, seriously or in propria persona, maintains that the $7^{\text {th }}$ definition is correct. Indeed, my argument is independent of the questions of whether Plato subscribes to any of the definitions of the sophist offered in the dialogue, whether he thinks that there is any single genuine kind corresponding to the sophist, and whether he holds that there is any corresponding definition of that kind. (For a discussion of these important questions, see Brown 2010, 151-171.) My assumptions are only that the claims he makes concerning truth and falsity in the $6^{\text {th }}$ definition, the discussion of images, and the $7^{\text {th }}$ definition are intended seriously, and that they imply a rather plausible (if metaphorical) account of truth and falsity. 


\section{The 'Official' Account of Truth and Falsity (263b1-d5)}

After the Eleatic Visitor and Theaetetus have addressed most of the issues taking up the core section of the dialogue, they offer a characterisation of truth and falsity:

[T1] Eleatic Visitor (=EV): And the true one says those that are, that they are, about you.

Theaetetus (=T): Of course.

EV: And the false one says things different from those that are.

T: Yes.

EV: So it says those that are not, but that they are (263b4-9). ${ }^{4}$

There are several important exegetical questions about these lines. My interpretation adopts a view which is fairly straightforward and dominant in recent literature. Focusing on the account of a true logos (statement), we can derive the following thesis:

A $\log o s$ ' $\mathrm{o}+\rho$ ' is true iff it says what is of/about $a$, i.e. being $F$, that ${ }^{5}$ it, i.e. being $F$, is (of/ about $a)^{6}$

where $a$ is the referent of 'o', being $F$ is what is described by ' $\rho$ ', and the logos ' $O+\rho$ ' says that being $F$ is of/about $a$ by means of its verb component ' $\rho$ ' (the '+' represents some form of predicative nexus). While it may appear that the official account describes truth as some type of correspondence with reality, I think that the text does not warrant this sort of interpretation. Rather, if anything,

4 I use Nicholas P. White's translation with occasional minor modifications.

5 That the hôs at 263b4 should be rendered as 'that', as opposed to 'how' or 'as', seems clear from 263b9; d1-2; see Frede 1992a, 417 f.; Crivelli 2012, 242f. (Crivelli translates the hôs as 'to be' but takes this as equivalent to the 'that' rendering); Hestir 2003, 3f.; Keyt 1973, 288-91; Szaif $1998,467$.

6 Frede 1992a, $417 \mathrm{f}$., argues that peri sou at 263b4-5 qualifies ta onta rather than esti on the basis of 263b11. While I agree with him, I think that nothing prevents us from thinking that peri sou is also logically (if not grammatically) required to qualify legei hôs esti: 'says of/about you that it is' or 'says that it is of/about you'. Crivelli 2012, 243, favours the more inclusive construal, in which the peri sou is to be understood as a qualifier common to both legei and ta onta. Hestir 2016, 183, formulates the account of a true statement slightly differently from my rendering. See his $\mathrm{P}-\mathrm{T}_{\mathrm{df}}$ : 'A true statement states of the things that are that they are about some s'. I do not think, however, that there is any substantive disagreement at this point between our views. 
this account is closer to the T schema of Tarski's semantic conception of truth. ${ }^{7}$ It is a deflationary, succinct, and elegant account which sets out truth in terms of a statement's saying of/about objects that what indeed holds of them holds of them. It posits that a logos has two components: the name- or, perhaps more accurately, noun-component 'o', which picks out an object, and the verb-component ' $\rho$ ', which picks out what is of/about the relevant object. Further, this logos is true just in case those components successfully perform their respective functions: 'o' picks out the object, and ' $\rho$ ' describes what is the case with that object. If so, the logos achieves truth by saying that what is about the object is. It is only an innocuous step from this to a proto-version of the T schema:

' $\mathrm{O}+\rho$ ' is true iff $a$ is $F .^{8}$

This, to be sure, is not a fully-blown, Tarskian, semantic account of truth (for instance, Plato does not, indeed cannot, invoke any notion of satisfaction). But it seems more congenial to Tarski's view than it is to any correspondence theory of truth which relies on stronger ontological commitments to some relation of correspondence, and to facts, states of affairs, propositions, or generally 'external', as it were, items to which a logos corresponds. Let us use the inelegant label 'semanticalist' for Plato's 'official' view of truth.

7 Hestir 2003, 13f., argues convincingly that Plato's account does not constitute any correspondence theory of truth but is more cognate with the Tarskian view. See also Hestir 2016, 191-193, where he shows that the rendering of hôs at 263b4 as 'that' (as opposed to 'as' or 'how') counts against the construal of Plato's conception of truth as some form of correspondence; and 212-8, where he argues in more detail against the correspondence construal and in favour of a more minimalist interpretation, in which Plato's conception of truth captures the realist intuition (countenanced in some versions of the correspondence theory) that a statement is true only if there is some external real-world item in virtue of which it is true. In Hestir's interpretation, however, this realist intuition does not require any commitment to a correspondence relation between statements and facts, obtaining states of affairs, objects, or what have you. Interestingly, in his 2016 monograph Hestir thinks that, while Plato's account of truth in the Sophist bears superficial similarities to the Tarskian view, it is not equivalent to, nor does it anticipate, a semantic conception in the manner of Tarski's view (210 f.).

8 I avoid a formulation such as

' $0+\rho$ ' is true iff $o$ is $\rho$

to discourage any comparisons with a correspondence theory of truth, in which there is a strict correspondence between linguistic terms ('o'; ' $\rho$ ') and real-world entities $(o ; \rho)$ or between a predicative sentence ('o $+\rho$ ') and a fact (that $o$ is $\rho$ ) or a state of affairs (o's being $\rho$ ). Cf. Tarski's own T schema: $X$ is true iff $p$ (Tarski 1944, 344). For a different formulation, see Hestir 2016, 185 f., the variants of his T-Schema: 's is $\mathrm{f}$ ' is true $\leftrightarrow s$ is $f$. 
Plato's semanticalist view of truth leaves unanswered several crucial questions. How does a statement - most importantly, a successful, true statement attain its 'of-ness' or 'about-ness'? Put differently, how does the name- or noun-component achieve its picking out an object such as you or Theaetetus? How does a true statement say that what is of/about you is? Alternatively, how does the verb-component succeed in describing the action, inaction, passion, feature, or what have you, which obtains of/about an object such as you or Theaetetus? ${ }^{9}$ It may be thought that it is an advantage of economy that the semanticalist view does not address these issues. For, after all, an account of truth need not resolve such difficulties. In the subsequent sections I shall argue that some of Plato's claims about truth in the $6^{\text {th }}$ definition of the sophist, in his discussion of images, and in the $7^{\text {th }}$ definition may nevertheless tackle these pivotal issues in an indirect (and admittedly metaphorical) fashion.

\section{Truth as Proportion I: Archery and Purging (226b1-231b8)}

In the sixth attempt to define the sophist using the method of division the interlocutors take up the discriminatory (dividing or separating) craft (diakritikê: 226c8) and focus on its purging or purifying kind (kathartikê: 226e1), especially as it applies to the soul. They argue that there are two psychic problems, two 'evils', which ought to be cleansed away by the purificatory art: wickedness and ignorance. It is important to note that the former is the counterpart to the bodily evil of disease, while the latter is analogous to the bodily deficiency of ugliness. ${ }^{10}$ At $228 \mathrm{a} 7-8$ it is claimed that, just as bodily disease, wickedness is a form of discord (stasis), a lack of cognateness (asuggeneia), and a discrepancy due to corruption of what is by nature cognate (or a corruption due to discrepancy of what is by nature cognate, depending on how one reads the text at 228a8). Since all of these notions are relational, it is fair to ask what is supposed to

\footnotetext{
9 Hestir 2016, 209-19, addresses these questions using a different approach than mine. In discussing what he calls Plato's 'conception' of truth (as opposed to his 'concept' of truth, which is innocuous and minimalist) he argues that Plato's conception is more robust than modern semantic conceptions of truth: for in it word meanings are reified and statement meanings are determined on the basis of such word meanings of a statement's constituents, plus those constituents' mode of combination in affirmations and denials.
}

10 Rosen 1983, 122f., emphasises this soul-body parallel. 
be in discord to what, what is not cognate with what, or what disagrees with what, in cases of wickedness. This question is answered by Plato at $228 \mathrm{~b} 2-10$ : a wicked person's beliefs or opinions (doxas) disagree with his or her appetites (epithumiais; presumably, akrasia is an instance of this case), his/her emotions (thumon) with his/her (feelings of?) pleasures (hêdonais), his/her reason (logon) with his/her (feelings of?) pains (lupais). In general, a wicked person's soul is populated by items which are in mutual conflict. This is a picture of vice as internal or psychic turmoil or even civil war, already familiar from $R e$ public IV. ${ }^{11}$

Ignorance, by contrast, is a form of lack of proportion (ametrias: 228a1011), just as bodily ugliness is. ${ }^{12}$ Again, proportion, or lack thereof, is a relational notion. In the case of our body it is obvious that the answer to the 'what lacks proportion to what?' question should be answered straightforwardly as follows: a body is ugly in case its parts (or some parts) lack proportion to each other (or to other parts). Thus, for instance, a head may be too small relative to the rest of the body, or if compared with the neck, and so may make the whole body ugly. Or a nose may be too large relative to the eyes and/or the ears, and so may blemish the whole face. It may be possible to extend this conception of bodily disproportion to cases in which a body or its parts lack proper fit to their environmental backdrop. Or we may wish to include instances which deviate dramatically from a natural norm. For example, an animal's body may be too large and cumbersome in a certain locale. Or an animal may have over-nourished and put on excessive fat if compared with characteristic members of its kind.

In the case of the soul and its ignorance, however, it is harder to answer the 'what lacks proportion to what?' question. Plato insinuates some possible replies in his simile with archery: ${ }^{13}$

11 Rosen 1983, 122f., refers to the conflicts discussed in the Republic to clarify this part of the Sophist.

12 Leigh 2009, 189, seems not to distinguish between the view of wickedness as discord and that of ignorance as disproportion; rather, she seems to think that disproportion, as well as discord, apply to the case of ignorance.

13 The archery simile is also deployed in the Theaetetus. Most notably, at 189c2-3, in the allodoxia section, Socrates uses the language of aiming at a 'being' (hou eskopei) and missing the mark (hamartanôn). In what follows I shall not discuss this important parallel with the Theaetetus as this would require a separate study. 
[T2] EV: Well, then, suppose something that is in motion aims at a target and tries to hit it [skopon tina themena, peirômena toutou tunchanein], but on every try passes by it [paraphora autou gignêtai] and misses. Are we going to say that it does this because it is properly proportioned [hupo summetrias] or because it is out of proportion [ê tounantion hupo ametrias]?

T: Out of proportion, obviously.

EV: But we know that no soul is willingly ignorant of anything.

T: Definitely.

EV: But ignorance occurs precisely when a soul tries for the truth, but swerves aside from understanding and so is beside itself [paraphorou suneseôs gignomenês, ouden allo plên paraphrosunê].

$\mathrm{T}$ : Of course.

EV: So we have to take it that an ignorant soul is ugly and out of proportion [ametron].

T: It seems so [228c1-d5].

In this image the soul is not willingly ignorant as it normally aims, or ought to aim, at truth and knowledge. An ignorant soul, however, systematically fails to hit those targets. Plato uses the ideas of swerving (paraphora; paraphorou), being beside oneself (paraphrosunê), and of some items being out of proportion to others (hupo summetrias tês pros allêla ê tounantion hupo ametrias). While all of these descriptions develop the idea of disproportion, they do not specify what lacks proportion to what. Some interpreters have argued that Plato probably thinks that the soul lacks proportion to the body or conversely. ${ }^{14}$ Their idea is, presumably, that a soul is ignorant in virtue of its being taken in by sense perception and belief or opinion (doxa), both of which are in some sense bodily or bodily-based. If so, sense perception and belief/opinion inhibit, interfere with, or interrupt the soul's aiming at the 'genuine', imperceptible, and intelligible truth. There is not sufficient evidence, though, for this construal within the context of the Sophist. Rather, this idea is more prominent in works such as the Phaedo and the Timaeus.

There is, however, an available answer to the 'what lacks proportion to what?' question, explicitly suggested by the wider context of the $6^{\text {th }}$ definition. Here is how the Eleatic Visitor describes the function of the purificatory experts who deal with a specific form of ignorance in a way distinct from those who practise admonition:

14 See Bluck 1975, 47-9. 
[T3] They cross-examine someone when he thinks he's saying something though he's saying nothing. Then, since he will go astray, these people will easily scrutinise his opinions [hate planômenôn tas doxas rha(i)diôs exetazousi]. They collect his opinions together during the discussion [sunagontes dê tois logois], put them side by side [eis tauton titheasi par' allêlas (sc. tas doxas)], and show that they conflict with each other at the same time on the same subjects in relation to the same things and in the same respects [tithentes de epideiknuousin autas hautais hama peri tôn autôn pros ta auta kata tauta enantias]. The people who are being examined see this, get angry at themselves, and become calmer toward others. They lose their inflated and rigid beliefs [megalôn kai sklêrôn doxôn apallattontai] about themselves that way, and no loss is pleasanter to hear or has a more lasting effect on them. Doctors who work on the body think it can't benefit from any food that's offered to it until what's interfering with it from inside is removed. The people who cleanse the soul, my young friend, likewise think the soul, too, won't get any advantage from any learning that's offered to it until someone shames it by refuting it [prin an elenchôn tis ton elenchomenon eis aischunên katastêsas], removes the opinions that interfere with learning [tas tois mathêmasin empodious doxas exelôn], and exhibits it cleansed, believing that it knows only those things that it does know, and nothing more [tauta hêgoumenon haper oiden eidenai mona, pleiô de mê; 230b4-d4].

The ignorance cleansed by these purificatory experts is of the worst type, that in which one thinks one knows but actually does not know (229c5-6). Leaving to the side technical or craft-related ignorance of this sort, and deeming admonition a less than successful remedy, Plato favours 'elenctic' teaching as the proper treatment. ${ }^{15}$ He suggests that this type of ignorance and pretence to knowledge consists in one's holding contradictory beliefs, which render one's belief-system inconsistent (230b1-d4).

The description of the elenctic treatment indicates that the relation of disproportion holds of beliefs (or opinions) relative to other beliefs (or opinions). Elenctic purifiers examine beliefs (230b5: tas doxas exetazousi); they juxtapose these beliefs and set them against each other (b6-7: sunagontes dê tois logois eis tauton titheasi par' allêlas); and they show that they contradict each other

15 My interpretation does not require that Plato is here actually defining Socrates' own elenctic practice. My only assumption is that a soul's pretence to knowledge is an 'ugly' and 'bad' state which ought to be purified, and that elenchus brings on this purification, and so contributes to a soul's psychic beauty (grasp of truth) and well-being. 
(b7-8: tithentes de epideiknuousin autas hautais hama peri tôn autôn pros ta auta kata tauta enantias). ${ }^{16}$ It seems fair to think that this type of contrariety is a form of lack of proportion, a conflict and lack of fit between beliefs. In this way, the elenctic purifier makes the would-be knower abandon their obstinate beliefs (230c1-2: megalôn kai sklêrôn doxôn apallattontai), those which prevent the believer from gaining any proper knowledge (d2-3: tas tois mathêmasin empodious doxas exelôn). Again, a belief which functions as an impediment to learning can be understood as being disproportionate: it is inimical but not congenial to a piece of genuine knowledge. If so, it prevents the believer from genuinely learning anything. There is an additional exegetical merit in taking beliefs as being disproportionate to each other in cases of psychic ugliness or ignorance. This interpretation fits well with the discord (stasis) model of psychic disease or wickedness, in which discord seems to obtain between internal states (such as beliefs and appetites, emotions and pleasures, reasons and pains, etc.).

It may be thought that this view of (attaining) truth is similar to coherentist approaches, in which (grasping the) truth consists in the coherence of a system of (held or believed) propositions. ${ }^{17}$ Plato does not, however, invoke any notions of mutual support, reciprocal explanation, or fitting-together, which could warrant this coherentist construal. Moreover, he suggests that this proportion model of truth stands in need of extension. ${ }^{18}$ It seems correct that consistency is a necessary condition for (attaining) truth. Put differently, if a system of propositions (or beliefs) contains inconsistent items, then, necessarily, falsity obtains somewhere in the system. But Plato seems to argue that once a system is purified from inconsistency, further inquiry is required to attain (knowledge of) the truth. ${ }^{19}$ It is clear

16 It is useful to compare this formulation with the so-called 'Principle of Potential Conflict' or 'Principle of Opposites' invoked at Republic IV, 436b9-c2.

17 This, and subsequent similar formulations, include bracketed terms for epistemic states (to attain, to grasp, to hold, or to believe) which qualify the notion of truth. Such formulations are not intended to conceal but to bring out a crucial question: are Plato's points about 'truth' claims about what truth itself consists in or are they claims about the epistemic criterion of truth - how we know that we have achieved it? I shall discuss this issue briefly towards the end of the present section and more extensively (if not fully) in section 5.2.

18 The notion of proportion used in the present and subsequent sections is not intended to imply that Plato's conception of truth is a precursor to a 'harmony' or 'agreement' version of the correspondence theory of truth, in which true statements are 'in harmony' or 'agreement with' facts, obtaining states of affairs, matters, objects, or what have you (see also Hestir 2016, 212-9). Rather, proportion is used in the specific senses set out in this and the next sections.

19 See Tarski 1944, 366-8, for an extremely interesting parallel to this idea. In dealing with the objection that his semantic conception of truth is not useful for resolving problems of scientific methodology, Tarski writes '[w]e know (if only intuitively) that an inconsistent theory must con- 
that the archery simile implies that one way in which to miss the target of truth is what could be called the 'laziness' or 'complacency' attitude of a would-be knower. In this case one is in a sort of self-deceiving state in which one is not even trying to hit the target at all as one falsely thinks one has already attained truth, and so is not inquiring into it. This, to be sure, need not entail that a would-be knower does not 'try' or 'intend' to speak truly in some attenuated sense. His or her self-deceiving state, however, prevents him or her from engaging in a genuine or proper attempt at speaking truly. For his or her 'trying' or 'wanting' to speak truly is drastically undermined by his or her false beliefs and pretence to knowledge. This pretence to knowledge is a type of ignorance. But it should be distinguished from a case in which one deliberately aims at a falsity (or at a non-truth). For this last case involves a person who actively attempts to hit some target. But this target is intentionally not the appropriate one, truth. I shall return to this point in Section 4, in my discussion of images, the $7^{\text {th }}$ definition, and its relation to the deliberate or unscrupulous deception effected by a sophist. ${ }^{20}$

tain false sentences; and we are not inclined to regard as acceptable any theory which has been shown to contain such sentences'.

20 The distinction between the complacent, ignorant would-be knower and the deliberate deceiver who intentionally aims at falsehood raises three important questions. (1) How could either of these two states be reconciled with Plato's earlier claim, made in [T2], 228c7-8, that 'no soul is willingly ignorant of anything'? In reply, it seems fair to think that the would-be knower, due to his or her ignorance, is not willingly ignorant of anything: for he or she just does not know that he or she is ignorant and that he or she should re-aim at truth. The deliberate deceiver, on the other hand, may be characterised by a sort of higher-order ignorance: while he or she knows that he or she is deliberately producing and propagating falsities, yet he or she may honestly believe that this sort of attitude will be truly beneficial to him or her (or even others). Had he or she known that this last belief is plainly false, he or she would have reconsidered his or her position and perhaps even given up his or her deliberate deception. Thus, even his or her soul is unwillingly producing and propagating falsities: for he or she would not wish to pursue this practice if he or she knew what is truly beneficial. (2) Does the deliberate deceiver's aiming at falsehood presuppose that he or she knows the truth but intentionally avoids it? The answer is, I think, negative: the deliberate deceiver need not know the truth in order to avoid it and aim at falsity instead. Rather, he or she need know only that his or her mental state is one of (potentially false) belief/opinion and ignorance/lack of knowledge. If so, he or she can decide to use this mental state to deceive others by making them adopt his or her falsities, without any need for properly discerning the truth and steering clear from it. (3) Is it even plausible that the deliberate deceiver always, systematically, or globally aims at falsehood? Wouldn't he or she be better off if he or she aimed at 'a little' truth, as it were, at least privately, for his or her own practical success? This question can be answered in two different, but not mutually exclusive, ways. First, one could draw the distinction between a deliberate deceiver's private mental states, which may well aim at truth (sometimes, for the most part, when expedient, or what have you) and his or her public logoi, which are false and intentionally rehearsed to deceive others. In a 
A further, perhaps more important, mode of falling short of the truth implied in the archery simile, however, is the following type of failure. One may well have completed the elenctic purification and be in 'the best and most healthy-minded' state of mind (230d5-6: beltistê goun kai sôphronestatê tôn hexeôn), in which one does not think falsely one knows (or one thinks one knows what one indeed knows and no more). Yet in seeking to hit the mark and attain the truth one still lacks, one may miss. As the archery simile makes clear, this type of failure should again be due to a lack of proportion or because of some disproportion (228c5: hupo ametrias). Ametria, therefore, could consist not only in one's system of beliefs being inconsistent but also in failing to hit the mark while seeking to attain the truth (by, e.g., shooting an arrow).

The slightly misleading image of the purging doctor developed at 230c4-d4 suggests this additional aspect of the archery simile and the proportion model of truth. ${ }^{21} \mathrm{~A}$ purging doctor removes internal inhibiting factors preventing the body

different approach, it is important to emphasise that the states described by Plato in this context but also later, in the discussion of image-making and the $7^{\text {th }}$ definition, do not, presumably, describe actual persons but distinct dispositions or states. No actual person (or hardly anyone) is always or utterly a complacent, ignorant would-be knower, about any and every subject. No actual deliberate deceiver - demagogue, sophist, or what have you - is globally and exclusively aiming at falsehood, even in prudential matters or cases in which his or her practical success is at stake. Rather, it is the states themselves of being a complacent, ignorant would-be knower and of being a deliberate deceiver which are systematically, firmly, and globally as described by Plato. (To be sure, even this last claim allows for such states to be inhibited, interrupted, or interfered with.) Actual persons, by contrast, may be predominantly characterised by a state but not fully 'possessed', as it were, by it. Or they may be approximating a state but not fully possess it. Or they may be placed at a penumbral position between states: sometimes acting on one sometimes on another. It may be helpful, at this juncture, to draw an analogy with ethical character traits: while (for instance) I may be generally tending towards enkrateia and decency, I may also, on occasion or when faced with difficult circumstances, be horribly akratic in respect of (for example) anger.

21 Rosen 1983, 130, notes that this image is confusing and potentially misleading. The reason is that so far Plato operates with a sharp distinction between psychic disease, vice or wickedness, and its treatment, on the one hand, and psychic ugliness, ignorance, and its treatment, on the other. While the image of a doctor would be more appropriate to the former case, it is used at 230c4- $\mathrm{d} 4$ for the latter: the elenctic purifier is like a purging doctor who cleanses the body from internal elements impeding the ingestion and/or digestion of nourishment. Generally, there is a question as to why Plato divorces so sharply psychic disease (wickedness) and psychic ugliness (ignorance). Even if he rejects (at this later stage of his philosophical development) the strictly intellectualist Socratic conception of virtue, he still seems to hold that wickedness depends on some form of ignorance, and that virtue depends on some form of knowledge. It is unclear, though, whether he would countenance a converse dependence of knowledge on virtue (or of ignorance on wickedness). At any rate, we may wonder whether the cognateness/ 
from taking in nutrition. The elenctic purifier removes internal inhibiting beliefs which are inconsistent and impede the soul's taking in knowledge (due to the soul's pretence to knowledge). The implication of this analogy is that after the elenctic treatment has been completed the truth-aiming archer has to attempt, to aim, and to hit the mark of truth in order to take in knowledge or escape ignorance. ${ }^{22} \mathrm{Had}$ it not been for the archery simile, the implication of the purging doctor image could have been simply that one ought to continue with elenchus until all inconsistency is decidedly uprooted. If this were so, the proportion model would imply that (attaining) truth consists simply in the consistency of propositions or beliefs. In this view, once consistency is in place, the target of truth is reached. By including the points about hitting the mark and taking in intellectual nutrition after removing internal impediments, however, the proportion model suggests that (attaining) truth requires more than simply elenchus and consistency. ${ }^{23}$

My proposal is that the archery and proportion models can be understood as combining the consistency requirement for truth (implicit in elenctic purification) with the idea that our true statements, propositions, mental states, etc. successfully refer to and/or describe an external, mind-independent reality. More precisely, the archery and proportion models suggest a normative ${ }^{24}$ and teleo-

health model of virtue is applicable to knowledge and truth too (or whether the discord/disease model of wickedness carries over to ignorance and falsity as well). Perhaps the 'confusing' and 'misleading' medical image offered at 230c4-d4. aims to re-align psychic health with psychic beauty, or psychic disease with psychic ugliness. It may be more economical, though, to agree with Bluck 1975, 47, that the distinction between wickedness and ignorance implies that there are purely intellectual errors, despite the fact that wickedness involves some form of ignorance and error. Leigh 2009, $187 \mathrm{f}$, insists that there is a close connection, even in the Sophist, of the soul's becoming or being beautiful not only with its becoming or being knowledgeable but also with its becoming or being virtuous.

22 Leigh 2009, 190, agrees that the negative process of elenchus 'does not itself end in the positive state of knowledge acquisition'.

23 It may be objected, at this juncture, that the theory of Recollection poses a threat to this idea of an external reality we have to aim at and hit. Even if we concede that Plato subscribes to the theory of Recollection in the Sophist (an exegetical claim which is not incontrovertible), this objection is not decisive. Plato's Forms in the middle dialogues, or his highest kinds in the Sophist, are external beings one has to grasp. This is so regardless of whether the terms Plato uses in the Sophist to pick out the highest kinds -'(the) Being', '(the) Same', or generally '(the) $F$ '- are naming (i.e. designating the relevant kind $F$ ) or generalising over the kind's members ('whatever or everything that is $F$ '). (For the distinction between the naming and generalising uses of kind terms, see Bostock 1984, 89-119.) If not everything we aim at as the truth is internal, the proportion model and the related archery simile do not seem to be purely consistency-based. 24 Notomi 1999, 153, also invokes the notion of normativity in interpreting Plato's likenesses (eikones). He argues that likenesses are normative in that apparitions (phantasmata) are defined in terms of them - as images which fall short of being successful or good likenesses - but not 
logical conception of truth. This conception is normative in that it posits that the excellent, beautiful, and naturally proportionate state of the soul is such as to aim at and hit the mark of truth (and so to have knowledge) without being impeded by inconsistency (mutually disproportionate, inconsistent beliefs). It is, by contrast, in virtue of a base, unnatural state of ugliness that our soul misses this mark of truth. ${ }^{25}$ Further, the conception is clearly teleological as it involves the notion of aiming at, and seeking to attain, the goal or telos (skopos) of truth (as well as achieving the goal of having knowledge).

It seems unnecessary to offer textual evidence in favour of the teleological aspect of the archery and proportion models, for [T2] clearly deploys teleological language. It is important, however, to examine whether the text supports any idea of normativity. Here are some important points which seem to underpin this idea:

227d4-11: As a type of purification, elenctic purging is understood as cleansing vices (kakias).

227d13-228a2; 228e1-5: Psychic beauty (hitting the truth) is taken as an excellence (aretê), whereas psychic ugliness as a vice (kakia).

228d1-2: The states of a soul's failing to understand (paraphorou suneseôs) and being beside itself (paraphrosunê) seem to be 'ugly' or unnatural (in the sense of being contrary to nature; see the prefix para- in paraphorou and paraphrosunê).

d4 and e5: Again failing to grasp the truth due to disproportion is linked to ugliness.

d10: While ignorance is not usually thought to be a form of wickedness (kakian), Plato strongly suggests that it should be deemed such. ${ }^{26}$

229c6 and 230b4: Failing to hit the truth is a case of a mistake (sphallometha), an instance in which we go astray in respect of our beliefs (planômenôn).

230c1-3: Ignorance in the form of pretence to knowledge is a state we ought to liberate ourselves from (apallattontai; apallagôn).

c3: Abandoning our pretence to knowledge is the most pleasant (hêdistên) of losses.

d2: Contradictory doxai which render our system of beliefs inconsistent are impediments (empodious) to the beautiful state of grasping the truth by learning.

conversely. While this idea is attractive and presumably compatible with my view, Notomi goes on to introduce (155) the claim that the successful or good likeness-maker is a philosopher who imitates god. In what follows I shall not discuss further this extremely important claim.

25 It seems plausible to think that Plato's normative view also involves corresponding 'ought'claims: one ought to avoid inconsistency; one ought to aim at truth; and one ought to hit the mark of truth. There is a subtle question, at this juncture, as to whether these 'ought'-claims follow exclusively from the claims about what is a soul's naturally beautiful condition or whether they require extra premisses. While it is important, this last question falls outside the scope of the present essay.

26 This point suggests that the boundaries between ignorance and wickedness (or between psychic ugliness and psychic disease, respectively) may not be as sharp as Plato initially implies at 226b1-228a11; see my note 21. 


\begin{abstract}
d1-3: Only a purged soul is in the pure state (katharon) required for reaping the benefits of learning (mathêmatôn onêsin).

d5-6: The state in which a soul thinks it knows only the things it actually knows and no more is described as the best (beltistê) and most healthy-minded (sôphronestatê).

e1-4: The state of a soul which has been purified by elenchus seems to be a necessary condition for well-being (eudaimona).
\end{abstract}

The notions of excellence, beauty, benefit, well-being, etc. (as well as their contraries) suggest that having a consistent system of beliefs as well as aiming at, and hitting, the truth are normative principles: we ought to seek to achieve such goals, and we ought to seek to avoid their contraries.

There is an important worry, however, about my proposed reading of this part of the Sophist. One may object that Plato is not really focusing on the notions of truth and falsity in his discussion of the elenctic purifier. One aspect of this objection is exegetical and can be easily addressed. Thus, Plato uses the term 'truth' (alêtheia) at crucial junctures of his argument. At 228c1-d2 it becomes clear that the target a soul willingly aims at (c1-2: skopon tina themena, peirômena toutou tunchanein) is that of truth (c10-d1: ep' alêtheian hormômenês psuchês). Similarly, what a soul ought to avoid, or the state it comes to be in when it fails to hit the mark, is one of error or falsity (229c5-6: hosa dianoia(i) sphallometha; 230b5: planômenôn).

There is, however, a more serious, conceptual side to this line of objection. Does Plato raise or tackle (albeit metaphorically or by using similes and analogies) the question of what the notion of truth itself consists in? Or is he rather focusing on the epistemological question of how we know that a statement, proposition, belief, or what have you is true or false? My reply is that his interest is not purely or primarily epistemological or justificatory. His question is not so much how we know that something is true or false or how we rationally support our claims to knowing. For he does not rely heavily on any notions of explanation, grasping the order of causation, or working out the aitia, as he does in the Meno. Nor does he invoke the notion of a logos in the reason-giving sense to spell out his model. Rather, his question seems to be about the nature of truth as codified in the official, semanticalist account outlined in Section 2. His rough and ready answer is that it consists in statements, propositions, beliefs, etc. aiming at and attaining the target of aletheia - 'truth' in the sense of 'the real thing', as opposed to the truth of standard truth bearers. Presumably, this skopos of 'truth' is (some relevant part of) external reality, what our true statements or beliefs successfully refer to and/or describe. There is, however, a prior requirement for a distinctive type of propositional truth in that a system of propositions or beliefs must be consistent to be able to aim well and hit the external mark. It may well be that the core 
items with which propositions or beliefs must be consistent are not any old propositions but some pre-eminent class of truths. Thus, for instance, the propositions which correctly describe the relations of communion between the (highest) kinds (251d5-257a12) or some version of (or approximation to) the Principle of Non-Contradiction (230b6-8) presumably constitute important propositions with which the rest of our propositions or beliefs ought to be consistent.

The archery simile (228c1-d2) and the medical comparison (230c4-d4) imply, however, that consistency is just necessary but not sufficient for truth. The additional requirement (that our true statements or beliefs successfully refer to and/ or describe an external reality) suggests a metaphorical reply to the two questions raised at the end of Section 2. The way in which true statements or beliefs achieve the result of being of/about an object, and of describing what obtains (of/ about that object) is by hitting the external mark being aimed at (having avoided the impediments of disproportionate, inconsistent beliefs). Admittedly, this is perhaps too metaphorical and not satisfactorily informative. The discussion of images and the $7^{\text {th }}$ definition of the sophist, however, seem to provide some further clarification of what hitting the mark of 'truth' consists in, or so I shall argue in the next section. ${ }^{27}$

27 My discussion of Plato's description of the elenctic purification of one's doxastic system from inconsistencies raises a serious worry: how should we proceed once we come to see that we hold contradictory beliefs? Which among our beliefs ought we to purify ourselves from and which ought we to retain? If we cannot answer this question, it is difficult to see how the model of elenctic purification could help us understand the nature of truth. This difficulty is not peculiar to my view. Rather, it is a worry that any interpretation of elenctic purification, and indeed Socratic elenchus, has to address. A good starting-point would be to rule out some clearly mistaken lines of approach. First, elenctic purification is not a proof of the falsity of an interlocutor's initial thesis - e.g., a refutation of a definition proposed by one of Socrates' respondents. Rather, at the end of an elenchus, the respondent has reasons (of various strength and plausibility) both for holding the initial thesis and for denying it. This is what it is to be in a state of elenchus-induced aporia (see Frede's extremely helpful discussion in his 1992b, 211f.). Second, it is not the case that the elenctic purifier - e.g., Socrates in the early Platonic dialogues - would act as an authority superior to the purified respondent. Nor would the elenctic purifier point the respondent in the correct direction, for instance by specifying which of the two contradictory beliefs is to be given up. Rather, working out which beliefs to retain and which to purify ourselves from is a personal achievement to be carried through by our own thought (Frede 1992b, $217 \mathrm{f}$.). More positively, progress could be made by adjudicating between the relative strength and plausibility of the reasons we have for each of the contradictory beliefs. It may be that the initially proposed definition is based on extravagant or unexamined reasons, while the belief contradicting it is based on deeply entrenched or highly plausible reasons. Or, while the initially proposed definition is something we thought we knew, the belief contradicting it is something we are more confident about, or something we would not easily give up. In this way we may infer the falsity of our initially proposed thesis or definition. Plato's view may allow for even further progress 


\section{Truth as Proportion II: 'Correct' and 'Incorrect' Images}

The discussion of image (eidôlon), likeness (eikôn), and appearance (phantasma), together with the $7^{\text {th }}$ definition of the sophist given at the end of the dialogue, seem to fill in some of the gaps in the view of truth as consistency of proportionate beliefs. ${ }^{28}$ These gaps are only alluded to by the model of elenctic treatment in the $6^{\text {th }}$ definition, with its insistence on hitting the external mark of 'truth' and taking in intellectual nourishment over and above accomplishing consistency. In the discussion of images it becomes clear that truth does not consist simply in the sort of proportion that consistent beliefs exhibit. It also involves the production (poietikê) of some type of image of beings, a product which somehow mirrors reality, or 'truth' in the sense of external reality. Hitting the external target of 'truth' is producing a certain type of 'correct image' of reality: one which aims at a relevant part of external reality, an original, and is accurate or faithful to that original's proportions and features. That Plato is emphatically referring to the external reality our true statements or beliefs pick out is clear from 234b5-10 and d2-e2. First, he contends that while illusory images are characterised by the same names as the real things (homônuma tôn ontôn), they deceive only mindless children. Second, he points out that experience and practice compels people who have been taken in by illusory images eventually to have a clear grasp on beings (anankazomenous enargôs ephaptesthai tôn ontôn). Given that a correct image successfully mirrors external reality, then, what does its correctness or success consist in ${ }^{29}$

in our endeavours in a variety of ways. On the assumption that we already possess the correct answer, in some version of the theory of recollection, we may think that further personal inquiry and purification will disabuse us of false beliefs and will furnish us only with true beliefs (Frede 1992b, 218). Alternatively, within the context of the Sophist, especially [T2], it may be that the soul itself by nature aims at the 'truth' and only unwillingly swerves away from it. Thus, further personal examination and purification will furnish us with a consistent and true doxastic system. Regardless of specific details, Frede (1992b, 214-6) is correct in arguing that the Socratic test for doxastic systems is extremely difficult to pass. It is not surprising, therefore, that we are at a loss, at least initially, as to which belief to maintain and which to abandon. It is difficult to know, about any and every proposition in our system of beliefs, all the other propositions which are logically related to it, and how they are related, so that we hold only mutually compatible beliefs about a given subject-matter.

28 The translations of the Greek eidôlon, eikôn, and phantasma I am offering are far from being incontrovertible. As my argument does not depend on whether these particular renderings are the most accurate or appropriate, however, I shall use them without discussing the alternatives. 29 Is there any evidence for the claim that (the grasp of) truth involves (producing or grasping) images? It is true that Plato does not directly or explicitly posit this dependency. But he suggests 
Before tackling this question, however, it is important to anticipate an obvious objection. Is it even legitimate to read the $6^{\text {th }}$ definition, the discussion of images, and the $7^{\text {th }}$ definition together, in the manner I am proposing? Or does this interpretation involve a misleading conflation of a rudimentary distinction between the elenctic practitioner and the image-producer? To defuse this form of objection, it is important to note, first, that my interpretation does not confuse the noble sophistic of the elenctic purifier with likeness- or appearance-making. Rather, it highlights the mutually complementary natures of a consistent system of propositions or beliefs (prevalent in the $6^{\text {th }}$ definition) and of 'correct', not simply consistent, descriptions of what obtains in reality (encapsulated in the notion of a true likeness). Similarly, the archery simile, which is pivotal in the $6^{\text {th }}$ definition, seems to 'cry out' for completion with a notion of what the result of hitting the mark of 'truth' consists in. The discussion of images and the $7^{\text {th }}$ defi-

that this dependency obtains as he links his discussion of incorrect images (those which distort an original's proportions and misattribute features to it) with disregarding the 'true' and 'bidding farewell to truth' (235e5-236a2: alêthinên; 236a4-6: chairein to alêthes easantes). By contraposition, correct images (those which preserve the original's appropriate proportions and features) should be constituents of the 'true' or truth. In particular, Plato holds that image-producing comprises a type of skill or craft which involves logous (234c2-7). The deceitful strand of this discipline influences those who stand at a distance from the truth (234c4: eti porrô tôn pragmatôn tês alêtheias aphestôtas) and creates images which yield the mere impression of truth (234c6: poiein alêthê dokein). The sort of image Plato focuses on in the present context (234c5) will be specified in terms of appearances, the incorrect type of image (e1-2: phantasmata). Moreover, in discussing how practice and experience liberates the victims of this sort of image-making from falsehood, Plato argues that they eventually achieve a clear contact with, or grasp of, beings (234d5-6: enargôs ephaptesthai tôn ontôn). It seems plausible to assume that the relevant type of 'contact' or 'grasp' is conceptual and/or linguistic in that it involves logous in some form or other, along the lines of $234 \mathrm{c} 2-7$. The idea, therefore, seems to be that practice and experience furnish us with true beliefs and/or true statements about beings. The conceptual and/or linguistic aspect of such true items is, presumably, what places some distance between our grasp and beings themselves. If so, it is also what renders these truths (correct) images or copies of, but not the same as, the 'ontic' originals. If our grip on beings did not have this conceptual or linguistic distance from beings - if it were not, in some way, an image or copy of ontic originals - Plato's claims would naturally entail an unpalatable result, an extreme strand of an acquaintance conception of knowledge. His view would imply that philosophy, knowledge, and generally the search for truth are strictly a matter of direct contact with beings, and so cannot be properly expressed through or in logos. There are several exegetical and conceptual reasons why this view would be implausible. Perhaps more conspicuously, in his philosophising and seeking of knowledge and truth, Plato himself has invested a significant amount of time and intellectual energy in producing logoi. Indeed, he has produced a vast body of logoi in his works. It seems fair to think that he would agree that logoi of this sort are (correct) images or copies of reality, which constitute (or help achieve) a clear contact with, or grasp of, beings. 
nition answer this question by identifying this result with producing the 'correct' image of reality. Second, and more importantly, the notion of proportion (summetria) seems to be fundamental not only in the $6^{\text {th }}$ definition but also in the discussion of images (235d6-236a2). One of the basic aims of the argument advanced in the present section is to set out the notion of proportion used in the discussion of images and to indicate its links to the earlier view of proportion.

Plato develops his view of images and the underlying notion of proportion in the following three stages:

(1) He makes some initial constructive points at 233c10-236d7.

(2) He raises important difficulties about the notion of an image at 239c9-240d1.

(3) He provides the final definition of the sophist and the corresponding sort of image he produces at 264b1-268d5, using the resources brought to light in the core section of the dialogue.

I shall examine each of these stages in turn.

\subsection{Constructive Discussion of Images (233c10-236d7)}

Plato divides the image-producing or imitative craft (eidôlopoiikê; mimêtikê) into likeness- (eikastikê) and appearance-producing (phantastikê; 235b8-10; d1-2; d6; 236c3-4; see fig. 1, row 6). He sets out this distinction as follows:

[T4] EV: One type of imitation I see is the art of likeness-making. That's the one we have whenever someone produces an imitation by keeping to the proportions of length, breadth, and depth of his model [kata tas tou paradeigmatos summetrias], and also by keeping to the appropriate colours of its parts [ta prosêkonta hekastois].

T: But don't all imitators try to do that?

EV: Not the ones who sculpt or draw very large works. If they reproduced the true proportions [alêthinên summetrian] of their beautiful subjects, you see, the upper parts would appear smaller than they should, and the lower parts would appear larger, because we see the upper parts from farther away and the lower parts from closer.

T: Of course.

EV: So don't those craftsmen say goodbye to truth [chairein to alêthes easantes], and produce in their images the proportions that seem to be beautiful instead of the real ones [ou tas ousas summetrias alla tas doxousas einai kalas]?

T: Absolutely [235d6-236a7]. 
Likenesses are images which retain the proportions of the original and use the appropriate colours (ta prosêkonta hekastois). They (and their makers) aim at the truth - they seek to mirror reality accurately - but of course they may fail to do so due to several reasons. Appearances, by contrast, do not retain the 'true' proportions (alêthinên summetrian). ${ }^{30}$ Plato offers the example of oversized statues or drawings. Thus, an oversized statue must have its higher parts (e.g., the head, shoulders, etc.) made larger in proportion to its lower parts (e.g., the legs, feet, etc.). In this way the fact that the former are normally observed from a greater distance than the latter would not affect the way they should appear to human observers.

It seems clear that the nature of appearances is determined by how something looks, by special features of the eyesight of the relevant intended observers (in this example humans), by facts about perspective and position, and other similar factors which are independent of the real proportions of the original (235e5-236a2; a4-6; b4-7; c3-4). ${ }^{31}$ If this is so, appearances (and their makers) either do not aim at truth or aim at not-truth, perhaps even falsity. In some cases an appearance may be the result of a lack of proper effort on the part of the maker, where falsity ensues due to not aiming at truth at all. This sort of ignorant or complacent appearance-maker is clearly deceiving himself or herself but need not be willingly deceiving others. Clearly, this sort of appearance-making is not Plato's focus in [T4]: for in that passage he is describing the highly skilful production of artefacts such as statues or paintings. Nothing, however, prevents the class of appearance-making from subsuming not only this skilled subtype, but also an unsystematic sort of ability for creating appearances (see fig. 1, row 9, first item). ${ }^{32}$ By contrast, in other, skilful cases, those Plato is focusing on in [T4], an appearance is produced as a result of actively, deliberately, and intentionally aiming at falsity or non-truth, perhaps also with the unscrupulous purpose of deceiving others. ${ }^{33}$

30 As noted earlier, the term alêthinên, as well as the phrase chairein to alêthes easantes at 236a4, suggest that truth and falsity involve Plato's notion of an image: while truth (partly) consists in a correct image, one which retains an original's proportions, falsity involves images which distort those proportions.

31 Notomi 1999, 149-153, makes some interesting points about the role of viewpoint in understanding appearances. Bondenson 1972, 2f., links the notion of distortion with the sophist's production of falsehood.

32 That appearance-making (as well as appearance) should be split into these two subtypes becomes clearer from 267b7-d2, where Plato distinguishes between appearances created with (or from) knowledge and those produced unknowledgeably or ignorantly. I shall take up this point in Section 4.3.

33 Leigh 2009, 195-8, interestingly compares Plato's points about perspective and the position of the audience in the case of artworks with certain features of sophistic arguments and with the ignorance, as well as the pre-existing beliefs, of the sophists' students. 
It is important to emphasise that the dominant notions of proportion and appropriateness fit elegantly with my interpretation of crucial parts of the $6^{\text {th }}$ definition. Thus, proportion is re-deployed in the present context, if for a slightly different purpose. Similarly, appropriateness seems to invoke the idea of normativity I introduced in the previous section. Both notions, however, are extended and used to supplement the earlier discussion. In [T4] proportion and appropriateness are not so much features which apply primarily to a system of propositions or beliefs. Rather, they seem also to hold good of characteristics of the original. For instance, an original is proportionate in virtue of certain relations between the dimensions of its parts and/or between the dimensions of the parts and the whole, or insofar as the colours it has fit with each other and/or with the whole. But there is a further claim, which seems to link the discussion of images to the $6^{\text {th }}$ definition: the proportions and appropriateness of the original must be represented accurately by the likeness (the 'correct' image), analogously to the way in which a good archer ought to hit the mark. Moreover, the likeness is a product which must have the same proportions between its parts as the original's parts, and retain the appropriate colours also possessed by the original. The claim that relations of proportion and appropriateness obtain between features or parts of the likeness corresponds to the earlier idea that a system of propositions or beliefs must have consistency-based proportion.

To take up the example of a statue: to be a good likeness, a statue must have the same proportions of dimensions between its bodily parts and/or between the parts and the whole as those between the original's bodily parts and/or between the original's parts and the whole. Similarly, not only is it required that the colour of the statue's eyes (for example) is the same as that of the original's eyes; it is also necessary that the colour is appropriate for the relevant type of bodily part of a certain type of bodily whole. This sort of appropriateness is clearly determined by the type of colour appropriate to the original's parts, as well as the type of whole that the original constitutes. Hence, a vivid purple seems inappropriate as an eye-colour of a human's likeness. ${ }^{34}$ Proportions between dimensions of bodily parts, as well as appropriate colours, involve a notion of what is proportionate and appropriate for part (of type) $A$ given other (types of) parts $B, C$, etc. of a (type of) whole $W$. Insofar as it holds of the parts of a likeness, this notion corresponds to the model of proportion used in the $6^{\text {th }}$ definition to characterise consistency relations of a proposition- or belief-system. It is crucial to note, however, that the

34 The example of a statue provided at Republic IV, 420c5-d5, seems helpful at this juncture. Interestingly, this example, too, invokes the notion of ta prosêkonta, what is appropriate to each part to yield a beautiful whole (d4-5). 
concepts of proportion and appropriateness apply not only to the likeness and the relations between its parts but also - and primarily - to the original. Thus, it is because purple is inappropriate as an eye-colour of a human that the same colour is inappropriate as an eye-colour of a human's likeness. ${ }^{35}$

Proportion and appropriateness are not, however, simply features internal to the original alone. Nor are they just internal to the likeness by itself. Rather, the proportion(s) and appropriateness of the likeness must also match, or be the same as, those of the original. There is, then, an additional relation of proportion and appropriateness of a likeness to its original, the external reality mirrored by it. For a likeness must be accurate or faithful to its original's features, structure, proportions, ratios, etc. These notions of accuracy and faithfulness of the likeness seem to correspond to the successful attainment of the target in the archery simile. This is a further way in which the $6^{\text {th }}$ definition and the discussion of images are intimately linked, with the latter developing the ideas introduced in the former.

An appearance, on the other hand, distorts the original's proportions. Does the contrast between it and likeness entail that Plato firmly places truth in the region of likeness, whereas he reserves appearance for falsity? Is it necessary that his appearances are wholly untrue or completely false and produced from ignorance? Moreover, does appearance require deliberate deceitfulness or intentional unscrupulousness towards others, the putative victims? Conversely, does

35 In the present account of original and likeness it seems that the original, too, has a type of proportion (or proportions) comparable with the consistency of a proposition- or belief-system. Does this imply that, in Plato's view, external reality (the original) also has to be consistent? And if so, is this implication a welcome result? It is fair to think that we can return an affirmative response to both of these questions. It would be odd if Plato required consistency on the side of propositions or beliefs as a necessary condition for their truth, while at the same time he thought that the external reality mirrored by propositions or beliefs is inherently inconsistent. Further, the Sophist seems to provide a picture of what consistency in reality may look like. In replying to the Late-Learners Plato argues that it cannot be the case that all or no (highest) kinds combine with each other (251d5-252d11). He concludes that some (highest) kinds combine with others, and goes on to specify which kinds combine with which, and in what fashion (252d1-260b8). It seems plausible to think that in doing so he offers a starting-point for an account of the sort of consistency characterising external reality. This is so under the reasonable assumption that the (highest) kinds constitute (the basic) parts of external reality, while their communion relations codify (part of) the way in which reality is consistent. The claim that the notion of consistency applies not only to propositions and beliefs but also to (parts of) reality seems congenial to Crivelli's point (Crivelli 2012, 24) about the distinction between propositional and ontological truth and falsehood. Plato seems to discuss the idea that reality itself must be consistent in his treatment of Protagoras' Secret Doctrine in the Theaetetus. I cannot discuss this issue in any detail at present. 
a likeness necessarily imply truthfulness, and does it require that it be produced knowledgeably? I shall argue that all these questions should be answered in the negative. It does not seem necessary that an appearance is false. Nor must it presuppose ignorance on the part of the appearance-maker. Similarly, a likeness need not be always true; nor must it be the product of knowledge.

It is worth, at this juncture, drawing a distinction between 'truth-falsity', on the one hand, and 'correctness-incorrectness', on the other. The claim that a likeness is a 'correct' image should not be conflated with the idea that it is (always or necessarily) true. Nor should we think that an appearance's being an 'incorrect' image entails its being (straightforwardly) false or (completely) untrue. The reason for this complication is that the view of truth introduced in the $6^{\text {th }}$ definition employs a normative and teleological notion of 'correctness': the naturally 'beautiful' state for our statements or beliefs is truth but this state is attained only ceteris paribus. Put differently: it is already good to seek to hit the mark, or to aim at the telos of truth, but it is still possible to miss or fail even if one sets the correct target.

Here are some conceptual considerations for allowing that a correct image may still fall short of truth or be produced by a mental state inferior to knowledge. A likeness-maker may be aiming at creating an (intentionally) accurate likeness but may fail (completely) to produce it due to (for instance) the difficulty of the original subject-matter, or due to lack of ability, or because external factors interrupted, inhibited, or interfered with his or her effort. Analogously, a mediocre or simply decent archer may aim at but fail to hit the mark if the target is too distant or camouflaged by environmental conditions. Even an excellent archer may miss the target if there is a sudden gust of wind right after the arrow has been released.

To undermine the idea that because it is an incorrect image, an appearance must be false, or be a product of ignorance, or involve deliberate deceitfulness, it is helpful to re-assess the example of a statue offered by Plato himself. It seems incontrovertible that it takes a significant level of expertise and knowledgeability to sculpt successfully a massive statue which looks proportionate. The good sculptor of such statues presumably possesses extensive knowledge of anatomy, perspective, human eyesight, etc. Moreover, while this sort of craftsman deceives by tweaking the original's proportions or features, he or she is not unscrupulous; rather, he or she seeks to produce a fine and beautiful statue for the aesthetic appreciation and delight of the beholders (I shall return to this idea in Section 4.3).

There is an additional important point about appearance and appearance-makers. It does not seem necessary that every appearance is made with a deliberate unscrupulous intention to deceive others. It is true that some appearances are of this sort. But others may be incorrect, inaccurate, and so false not 
because their maker wished to deceive any victims. Rather, they may be incorrect and false as a result of someone's not realising that his or her attempts at truth-attainment are insufficient. If so, this person is not deceiving anyone other than himself or herself. This is an important point as it forges a stronger link to the $6^{\text {th }}$ definition. A system of beliefs may be incorrect and false not because the beliefholder unscrupulously intends to deceive others with his or her beliefs. Rather, it may be so due to that person's thinking (falsely) that he or she already has hit the truth and has knowledge. If so, he or she would not seek to inquire into truth. This case involves self-deception but not unscrupulous or intentional deceit of others. It resembles the lazy or complacent state of the would-be knower who has not been reduced to aporia by elenchus. Another way to make this point is by exercising caution as to the scope of the negation as it applies to the phrase 'to aim at truth': while the intentional, unscrupulous, and other-deceiving appearance-maker aims at not-truth (or aims at falsity), the lazy, complacent, and self-deceiving appearance-maker does not aim at, or (more precisely) does not inquire into, truth (as he or she thinks he or she already possesses the truth; see fig. 1, row 9).

There is also strong textual evidence for denying the identity of truth with likeness and of falsity with appearance. First, at 260c6-10 falsity (pseudos) and deception (apatê) are thought to be endemic not only in appearances but also in likenesses and, quite generally, in images. ${ }^{36}$ Plato seems to argue that falsity entails deception, while deception (presumably together with falsity) entails that images -both likenesses and appearances - are virtually omnipresent. That this is not an aberration is obvious from $264 \mathrm{c} 10-\mathrm{d} 2$, where the same point is made about falsity as a prerequisite for images - likenesses and appearances alike. Second, at 267b7-268a9 Plato claims that appearance-making can be possessed and exercised either with or without knowledge. Assuming that knowledge is factive and that ignorance is error-entailing, ${ }^{37}$ this implies that appearances can (in some sense) be true when produced with knowledge, and erroneous when

36 See Szaif 1998, 402; Brown 2010, 161; Crivelli 2012, 25; 26 n47.

37 The relation between ignorance and falsity is less clear than that between knowledge and truth. I may ignore that $p$ while at the same time $p$ is true. If so, ignorance is not falsity-entailing. It seems correct, though, that this sort of 'lucky' ignorance is something similar to unjustified or chancy true belief. In another view of the grammar of 'to ignore', the fact that I ignore whether $p$ seems to allow that $p$ may be true. But it may suggest that I have no epistemic access to $p$ at all: I do not even entertain or think about $p$ or whether $p$ at all. Both construals seem to suggest that, while ignorance does not necessarily entail falsity, it nevertheless implies some serious sort of error. For this reason, I have opted for the claim that ignorance is error- (rather than falsity-) entailing. 
produced with ignorance. ${ }^{38}$ Thus, truth is not completely banished from the region of appearance. On the additional plausible assumption that this division carries across to likeness-making too, it follows that a likeness can be made either with knowledge, and so be true, or without knowledge (in the manner of doxa, for example), and so be false. Falsity can, therefore, occur not only on the side of appearances but also on the side of likenesses (see fig. 1, row 8). ${ }^{39}$

The crucial question, at this juncture, is whether the concept of apatê invoked at 260c8 necessarily entails a deliberate and unscrupulous attempt to mislead or deceive others. It seems fair to think that, just as Aristotle in several places (see APo. I.2, 72a37-b4; Metaph. Ө.10, 1051b25-28; 1052a1-4), Plato, too, may be using apatê in the sense of error, mistake, or falsity quite generally. Clearly, in some cases - those of the sophist's appearances - the error and falsity are of the unscrupulous type, which deliberately and intentionally deceive others. In other cases, however, for example those of erring likenesses or non-sophistic false appearances, the apatê may be non-deliberately-deceitful or non-unscrupulous: a mere error or mistake, an innocuous type of falsity. Hence one may, for

38 One may object, at this juncture, that my inference from knowledge to correctness and truth (what I labelled 'factiveness') is not sound. For, in Plato's view, the possession of knowledge is the best possible preparation for doing the wrong thing in any science or craft. For instance, a good medical training makes someone excellent also at physically harming others. By analogy, it would be claimed, a knower is best placed to manufacture falsehoods. There are two points in response to this objection. First, the thesis that 'knowledge is of opposites' applies primarily to skills, crafts, or arts. It does not generally characterise knowledge in the Platonic sense of epistêmê, sophia, or phronêsis. In this latter sense, one would not be inclined, nor would one want to, pursue falsehood in any way. Second, and more importantly, the general Platonic notion of knowledge I am relying on should be viewed as being constrained by truth and goodness. This is how Plato conceives knowledge in (for example) the central books of the Republic: the Form of the Good is identified with truth not only in the propositional but also in the 'ontic' sense of reality. If so, a genuine knower is a knower of truths and does not, indeed cannot, pursue falsehood. 39 Rosen 1983, 147, seems to think that eikones are necessarily true, while phantasmata false. Later, though, he argues that 'if icons (or non-fantastic $\varepsilon$ "' $\delta \omega \lambda \alpha$ ) also contain falsehood, they must [...] do so in a way different from fantasms'. His final formulations (312) express uncertainty as to whether falsity is found only in phantastikê or also in eikastikê. Gulley 1962, 149f., does not notice these two points, nor does he seem to realise that truth and falsity may be found in both likenesses and appearances alike, but thinks that Plato is confused in his account of images, likenesses, and appearances. Leigh 2009, 192-194, seems to argue that likenesses are necessarily faithful, and so always true, whereas appearances are unfaithful, illusory, and so just false. But she also claims (199) that 'artistry, unlike sophistry, aims to put the audience in mind of a true or accurate idea of the intentional object'. This seems to allow for some notion of truth within the region of appearance but rules out truth in the case of sophistic appearances. Her final formulations, however, suggest that she takes likenesses as faithful in the sense of being true: 'likenesses are images or representations that are not false' (206). 
instance, speak falsely unknowingly or unwillingly. Indeed, one may be seeking to hit the mark and attain the truth but fail to do so for reasons unrelated to malicious deception. Statements or beliefs of this sort could be subsumed under the heading of (non-true or false) likenesses: for, insofar as they aim at truth, they are correct images, despite the fact that they fail to be true. It seems plausible to understand falsehoods of this sort as the items that some subtype of belief or opinion (doxa) is set over. Doxa is not factive but may be either true or false. In either case it is distinct from knowledge. But if there is a form of doxa (perhaps the paradigmatic form of doxa?) which aspires to the attainment of truth, it, and the items it is set over, can be characterised as correct images (likenesses) even if they do not hit the mark (see fig. 1, row 8, second item).

A different sort of case is that of the unexamined false believer from the $6^{\text {th }}$ definition, who falsely thinks that he or she has knowledge. This seems to fall under the heading of appearance: for the would-be knower does not inquire into truth but complacently thinks he or she already possesses it. His or her incorrect image is false but is not deliberately or unscrupulously deceitful of others. A would-be knower is clearly under some form of self-deception or illusion due to the false belief that he or she possesses the truth. But this apatê is not necessarily deliberate, wicked, or malicious towards others. This is compatible with the possibility that a false statement or belief of a would-be knower may accidentally deceive others (perhaps the gullible). Even so, this type of falsity is an appearance which is not unscrupulous. It is exemplified by the state of unexamined complacency in that its possessor does not attempt to re-aim at the truth, even though he or she ought to do so. It may even be deemed lazy as it preserves the self-deceiving state of his or her pretence to knowledge and the related form of falsity. But it is not intentionally deceitful of others for base purposes (see fig. 1, row 9, first item). The sophist's appearance, by contrast, is presumably unscrupulous as it aims at non-truth or at falsity. This is clearly a wicked type of apatê, deliberately intended to deceive others (see fig. 1 , row 9, second item). ${ }^{40}$ To examine this issue in detail, however, it is necessary to discuss the final part of the dialogue where the $7^{\text {th }}$ definition of the sophist is offered. Before taking up this task, it is useful to go through Plato's aporiai about the notion of an image.

40 Crivelli 2012, 25 f., argues for a different view of apatê in which deception is intertwined with both likeness and appearances: while likenesses are false but are based on a true belief about a feature that the original actually possesses, appearances are false twice-over as their falsity is based on a further false belief about a feature not actually had by the original. 


\subsection{Aporiai about Images (239c9-240d1)}

The interlocutors agree that, if the account of truth and falsity in terms of an image mirroring an original is to be promising at all, it is necessary to define what an image is. Unsurprisingly, Theaetetus makes the usual mistake Platonic definers commit. He lists particular cases or types of image, as opposed to stating what an image is (239d7-9). Theaetetus understands quickly what he is being asked to provide and offers an attractive definition:

[T5] T: What in the world would we say a copy is, visitor, except something that's made similar to a true thing and is another thing that's like it [to pros talêthinon aphômoiômenon heteron toiouton].

EV: You're saying it's another true thing like it? Or what do you mean by like it?

T: Not that it's true at all, but that it resembles the true thing [oudamôs alêthinon ge, all' eoikos men].

EV: Meaning by true, really being [ara to alêthinon ontôs on legôn]?

T: Yes.

EV: And meaning by not true, contrary of true [to mê alêthinon ar' enantion alêthous]?

$\mathrm{T}$ : Of course.

EV: So you're saying that that which is like is not really that which is [ouk ontôs on ara legeis to eoikos], if you speak of it as not true.

$\mathrm{T}$ : But it is in a way.

EV: But not truly, you say.

T: No, except that it really is a likeness [plên g' eikôn ontôs].

EV: So it's not really what is, but it really is what we call a likeness [ouk on ara ontôs, estin ontôs hên legomen eikona].

$\mathrm{T}$ : Maybe that which is not is woven together with that which is in some way like that - it's quite bizarre [240a7-c3].

Three important points arise from [T5]. First, it is clear that the focus is on a notion of 'truth' or 'the true'. But it seems plausible to understand this as 'reality' or 'what is real'. The concept of 'what really is' (240b3: ontôs on) and the contrast with what really is not (b7: ouk ontôs on) suggest this interpretation. Second, similarity or resemblance (240a8: aphômoiômenon; b2: eoikos) should be compared with the use of similarity at 231a4-b1 (homoiotêtas). Plato implies that we should exercise caution in our use of the notion of similarity or resemblance: for this notion will regenerate the paradoxes of non-being and falsity. Third, while Theaetetus defines an image in terms of difference from the real (240a8: heteron), he 
replies to the Eleatic Visitor's question as to whether an image is an extra real thing different from, and over and above, the original real thing by saying that it is 'in no way' real but it resembles the real (240b2: oudamôs alêthinon ge, all' eoikos men). Moreover, he also agrees that it is contrary to the real and so is what truly is not (b5: to mê alêthinon ar' enantion alêthous; b7-8: ouk ontôs on ara legeis to eoikos). This slip from difference to contrariety and complete unreality is to be expected at this stage of the dialogue, before the core section, where contrariety is discarded and difference favoured as a fundamental constituent of the accounts of negation, non-being, and falsity. ${ }^{41}$

At 240b9-c3 Theaetetus seeks to reinstate an image's existing or being real in some sense, the sense of an image (240b11: plên g' eikôn ontôs). It is not necessary to construe the use of eikôn at 240b11-c1 as invoking the concept of the 'correct image' or 'likeness'. Theaetetus's definition is a rough-and-ready characterisation, an underdeveloped and ungrounded account of the generic type of an image. This account seems correct (in principle) but must be grounded on some conception of negation, non-being, falsity, and false belief. This is the task of the Sophist's core. But the notions of difference (as opposed to contrariety) and of existing or being real qua image are crucial and successfully latch onto basic features of an image. If indeed this is a pre- or proto-theoretical definition of the genus image (despite the use of eikôn at 240b11-c1), it is clear that both a 'correct' image (likeness) and an 'incorrect' image (appearance) are different from the real or are non-genuinely real: for they are not originals.

This significant claim clearly entails simply that images are different from what they are images of, not that they are non-existents (for this last, stronger claim enantion is presumably required). To set out this implication it is helpful to examine the contrast between an object having a feature - say, pale Socrates - or a state of affairs - Socrates' being pale - or some other external entity of a similar sort, with a statement, proposition, or belief about/of this object plus its feature, or that state of affairs. The external or mind-independent entity is 'true' (alêthinon) in the sense of being real, original, genuine, or a model, whereas the mind-dependent items are not 'true' in this sense but are still real: for they are real propositional items or mental states of/about a thing which putatively describe a feature of that thing. If this sort of non-genuineness is common to both likenesses and appearances, however, what differentiates these two species of an image? The discussion so far suggests an answer to this question in terms of the normative-teleological account of truth, together with

41 Notomi 1999, 157, notes the significance of the slip from heteron to enantion at $240 \mathrm{~b} 5$. 
the distinction between retaining and distorting the 'true' proportions of the 'real' original. ${ }^{42}$

The tentative definition of an image offered in the aporetic section of the Sophist keeps in play all the important ideas of the preceding discussion. It is compatible with the archery simile and the related normative-teleological conception of truth alluded to in the $6^{\text {th }}$ definition. There is an obvious (if implicit in Plato's argument) parallel between the success- (or failure-) condition or state of the truth-seeking or statement-making archer, on the one hand, and the product of an image-maker, on the other. To develop the implications of this parallel, we could conjecture that the result or product of an archer's endeavours may be a bull's eye shot, a correct and true image - a likeness which is true. Or it may be a miss, which comes in several different guises: it may be a false but 'correct' image, a likeness which was aiming at truth but falls short of it; or an incorrect image, a false appearance of a complacent would-be knower; or a sophist's false appearance intending to deceive others. Moreover, Theaetetus's account of an image can accommodate the claims made earlier that an image is successful insofar as it is accurate or faithful to the original's proportions, whereas it fails if it distorts those proportions. While all images are different from the 'real' original but bear some form of resemblance to it, some are 'correct' in that they aim to keep the original's proportions, others are 'incorrect' in that they either do not seek to be accurate in this way or they deliberately and unscrupulously seek to be unfaithful to the original's 'true' features. In the next section I shall clarify further these important claims.

42 Bluck 1975, 59, points out that likenesses are images and so differ from reality. Notomi 1999, 135 f., insists that the Sophist does not have a simple 'picture' model of language. His criticism is presumably directed against interpreters such as Tilghman 1969, 158-160: 'For Plato [...] a sentence is meaningful because it in some way reflects reality; if it is to be meaningful, language must somewhere make contact with the world [...] [F]or [...] Plato [...] a sentence is a logical representation of the ontological structure of the world [...] The sentence [...] couldn't be anything but a representation of reality in symbols [...]'. He concludes that Plato explicitly held a picture theory of meaning in which true statements are likenesses. While Tilghman notes the distinctions between 'true' proportions and 'distorted' proportions, and between likeness and appearance, he overlooks the point that error and falsity occur in the regions of both likeness and appearance. Bondenson 1972, 2f., also seems to take Plato as subscribing to a simple 'picture' model of truth and falsity. He emphasises that the sophist's false statements are 'distorted [verbal] images of what they purport to represent'. Again, though, he does not account for Plato's remark that even likenesses contain error and falsity. 


\subsection{The $7^{\text {th }}$ Definition (264b11- end)}

The final section of the dialogue defines the sophist on the basis of the distinction of image-making into likeness- and appearance-making (see fig. 1, row 6). ${ }^{43}$ Here is the definition offered at the very end of the Sophist:

[T6] EV: Imitation of the contrary-speech-producing, insincere, and unknowing [tês doxastikês: opining] sort, of the appearance-making kind of imagemaking, the word-juggling part of production that's marked off as human and not divine. Anyone who says the sophist is of this 'blood and family' will be saying, it seems, the complete truth.

T: Absolutely (268c8-d5).

Plato emphasises, from the very outset of the dialogue's last section, the claim (already made at 260c) that falsity obtains throughout the entire genus of an image: both likeness and appearance involve falsity (264c11-d2: oute eikôn oute eidôlon oute phantasma eiê to parapan ouden dia to mêdamôs mêdepote mêdamou pseudos einai). ${ }^{44}$ Plato does not, however, identify image-making with unscrupulous appearance-making. Nor does he equate the generic notion of an image with false and deceitful appearance. His formulation at $264 \mathrm{~d} 5-7$ suggests that the deception-expertise grows out of (but is not identical with) the disposition which produces images (enchôrei dê mimêmata tôn ontôn einai kai technên ek tautês gignesthai tês diatheseôs apatêtikên). This is unsurprising as an appearance is a type of image and appearance-making a form of image-making. Moreover, the problematic notion of similarity or resemblance (already discussed at 231a4-b1 and 240a7-8) is re-deployed at 266d7-8 (homoiômatôn) alongside the concept of an image (d4: eidôlon; d9: eidôlourgikês) as a generic characterisation applying to both likenesses and appearances.

The distinction between likeness and appearance is developed with a further, crucial division of appearance into being knowledgeable and being non-knowledgeable or ignorant (267b7-9: hoi men eidotes [...] hoi d' ouk eidotes [...] agnôsias te kai gnôseôs; d1-2: mimêtên dê touton ge heteron ekeinou lekteon oimai,

43 It is remarkable that, while at $235 \mathrm{~b} 8-236 \mathrm{~d} 8$ the interlocutors are presented as being at a loss as to whether to place the sophist under likeness- or under appearance-making (see especially 236c9-d4), yet at 264b11-268d5. they straightforwardly define the sophist in terms of appearance-making, without offering any clear reason for this classification.

44 Arguably, the pleonastic expression dia to mêdamôs mêdepote mêdamou pseudos einai is precisely Plato's way of emphasising this claim. 
ton agnoounta tou gignôskontos; see fig. 1, row 8, third and fourth items). ${ }^{45}$ Two remarks are in order at this juncture. First, the term 'imitative-expertise' (mimêtikê) is now a species-term for an image-maker who does not deploy external instruments but uses just himself or herself to produce an image. This usage differs from Plato's earlier practice in which he applied 'imitative-expertise' and 'imitation' generically to the entire region of image-making and image (234b1-10: to mimêtikon; mimêmata). ${ }^{46}$ Second, two important divisions drawn upon the 'right-hand-side', as it were, that of appearance, seem also to apply to the 'lefthand-side', the side of likeness. It is plausible to think that a likeness, too, may be produced using either external instruments or just oneself (see fig. 1, row 7, first and second items). Further, and perhaps more controversially, a likeness could be divided into being knowledgeable and being unknowledgeable (or ignorant; see fig. 1, row 8, first and second items). The latter type of likeness could be compared with some form of belief or opinion (doxa) which falls short of knowledge but may still be 'correct' in that it is truth-aiming, even though it is not factive. The difference of this sort of doxa from that associated with appearances is that the latter does not aim at the truth or deliberately aims at non-truth or falsity.

Several difficult questions arise from these remarks. First, what is the criterion with which to draw the line at this level and carry over to likeness only the following two divisions: external instruments - oneself; and knowledgeablyunknowledgeably? Why not think that there is also a type of likeness which is produced intentionally as a false likeness with the maker's awareness of his or her own ignorance, as is the case for appearance? The criterion for ruling out this last sort of false likeness should be determined by the differentia which marks off likeness from appearance. To circumscribe this differentiating feature I shall draw on the normative-teleological conception of truth and the distinction between seeking to retain and distorting the original's proportions. ${ }^{47}$

45 It should be noted that my view differs from Gill 2012, 242-4. She places both the philosopher and the true rhetorician under knowledgeable appearance-making (phantastikê). As will become clearer in the present section, my view entails that a philosopher may be dealing in either true likenesses (correct images) or in knowledgeable, and so true, appearances (incorrect images). What characterises the philosopher's expertise and his or her products are the features of knowledgeability and truth. These, however, are placed not only under likenesses or only under appearances but seem to apply to specific regions of both of these subtypes of the genus image. 46 See Notomi 1999, 280, for an excellent analysis of this point.

47 Rosen 1983, 159, notes the importance of the end one directs one's 'comprehensive energies' to but does not provide any further argument or textual evidence for this view. He also emphasises (171) the importance of the accuracy versus the inaccuracy of reproducing the original's proportions. See also Notomi 1999, 148-150. 
The starting-point of my argument is that truth, as well as falsity, figure in both likeness and appearance, under the guise of the knowledgeably - unknowledgeably distinction (see fig. 1, row 8). It seems correct to maintain that this last distinction is equivalent to (but not the same as) the distinction between truth and error/falsity: for knowledge is factive and truth-entailing, whereas lack of knowledge may relate to propositional items which are either true or false - in the case in which non-knowledge entails belief or opinion (doxa) - or to items which are erroneous or plainly false - in the case of ignorance. On the side of incorrect image (see fig. 1 , row 8 , third and fourth items), an appearance is divided into that which involves knowledge and that which involves lack of knowledge or ignorance (it may be significant that both formulations - hoi ouk eidotes at $267 \mathrm{~b} 8$ and agnoounta at d2 - are used). A further plausible assumption is that the knowledgeable state involved in this division need not be too fine-grained. It is simply some form of knowledge and as such must be factive, truth-entailing, and infallible. This warrants the minimal conclusion that the division maps onto the distinction between truth and non-truth or falsity. Indeed, Plato uses the less demanding terms eidenai, gnôsis/gnônai, and gignôskein (267b7-12) steering clear from characterisations such as dianoia, nous, or any other more exalted mental state. There is an occurrence of epistêmê at 267e2-3 but it is glossed as historikên, so it may well signify an attenuated notion of epistêmê. The division knowledgeably-unknowledgeably, therefore, entails the contrast between a factive or truth-entailing state and a non-factive or even erroneous state.

My additional suggestion is that this contrast also obtains in the case of correct images, likenesses (see fig. 1 , row 8, first and second items). Insofar as it is a correct image, however, a likeness - whether it is factively just true or non-factively either true or false - cannot involve not aiming at truth, the sort of attitude characteristic of the unexamined and complacent would-be knower. Nor can it involve aiming deliberately or intentionally at non-truth or falsity seeking to distort the original's proportions in an unscrupulous, deceitful, or malicious fashion. For, on the basis of the normative conception of truth, a correct image is the product of a naturally good mental state, linguistic practice, propositional attitude, or what have you: it is the analogue of harmonious or proportionate bodily beauty. Further, and more importantly, as the teleological conception of truth suggests, it is also a product of aiming at and seeking to attain the target of truth. This target is to achieve and/or retain the original's 'true' proportions. ${ }^{48}$

48 It is certainly possible that a false statement or belief held by a likeness-maker - a decent but unsuccessful believer or opiner - is extensionally (or de re) the same as one used by (for example) an appearance-maker in order to deceive. But there is an important intensional (or de 
This does not, to be sure, rule out the possibility of error. A correct image may miss the target of truth for several reasons. It may be the product of an insufficient ability or a lack of expertise - a case of being unknowledgeable. Or it may be based on expertise but still miss the mark of truth due to extremely difficult external conditions, interferences, inhibitions, or interruptions - a case where knowledgeability faces local or temporary failure. Indeed, a likeness may hit the mark because of good luck or as a matter of fluke - a case where the relevant truth-bearer would attach to a doxa-like state, analogous to, but not identical with, the doxomimêtikên of $267 \mathrm{e}$. While this doxa case involves truth, it does so only incidentally, and therefore still falls short of knowledge: it is not false in the manner of doxomimêtikên but it is a merely accidentally true doxa.

These considerations suggest that, though it is a correct image, a likeness may itself be either true or false. Moreover, it may be true in the way in which factive mental states necessarily range over true propositions (see fig. 1, row 8 , first item). Alternatively, it may be either true or false in the way in which a belief or opinion takes as its object either a true or a false proposition (see fig. 1 , row 8, second item). In all these cases, however, the telos is to hit the mark of 'truth', and to retain the original's 'true' proportions and 'appropriate' features. A knowledgeable correct image (a likeness with knowledge) includes truth-bearers which normally attach to mental states such as knowledge, wisdom, expertise, intelligence, understanding, etc. An unknowledgeable correct image (a likeness without knowledge), by contrast, encompasses all those truth-bearers which couple with doxa-like states and are either true or false. Neither sort of likeness, however, involves any complacent or lazy not-aiming at truth due to pretence to knowledge. Nor does it involve any deliberate distortion or intentional aiming at falsehood for deceitful purposes. The entire region of likeness, therefore, aims at truth, seeks to avoid error or distortion, and pursues the accurate or faithful rendition of the original's proportions.

There is a further difficulty. Because the division knowledgeably-unknowledgeably also applies to the region of appearance, the equivalent distinction between truth and falsity must carry across to this type of image too (see fig. 1 , row 8, third and fourth items). While an appearance is an incorrect image, it is possible that it be produced with knowledge. But if so, it too could be true.

dicto) difference, one captured by the normative-teleological conception of truth. Suppose that $p$ is false. A decent but unsuccessful likeness-maker states or believes that $p$ as something being aimed at truth, and as a result of a decent or good propositional attitude, linguistic practice, or mental state. An appearance-maker, by contrast, states or believes that $p$ either as something not being aimed at truth or as something being aimed at falsity. At any rate, in this last case, $p$ is held as a result of a less than optimal propositional attitude, linguistic practice, or mental state. 
Indeed, it could subsume truth-bearers which are factively true insofar as they attach to knowledge-type mental states. On the other hand, an appearance could also be false insofar as it is produced with ignorance. Plato seems not to allow any logical space at this juncture for an appearance which could be either true or false: for this sort of image is categorised under the decent (or at least not unscrupulous) truth-aiming (but non-factive) likeness usually associated with doxa-like states. Ignorant appearances seem to be erroneous or just false, with some cases showing awareness of the ignorance and error, others being unaware of these shortcomings (267e11-268a4).

If we apply the conceptions of truth discussed in previous sections to this interpretation of appearance, we can derive two important results. First, the normative conception indicates that insofar as they are incorrect images appearances are not naturally beautiful or fine; they may look like the correct, beautiful, and beneficial images but are not such (or are not optimally such). ${ }^{49}$ Second, the teleological conception implies that they are characterised in fundamentally negative terms. For, instead of aiming at, and seeking to attain the mark of truth, instead of pursuing accuracy and faithfulness to the original's proportions, they either do not aim at truth at all or they actively and deliberately aim at non-truth in the form of falsity, illusion, and deception. The first disjunct of this negative characterisation picks out a type of ignorance and falsehood in which the mark is missed but there is no corrective or repeated attempt to re-aim. This should be exemplified by the complacent and lazy state of the would-be knower, an unnatural, ugly state of a lack of (self-)examination by elenchus (see fig. 1, row 9, first item). While this state does not intrinsically involve any deliberate or unscrupulous deception of others, it does burden its possessor with the self-deception of his or her pretence to knowledge. The second disjunct seems to correspond to the type of appearance which is allocated to the unknowledgeable appearance-makers ultimately identified with (the demagogues and) the sophists (see fig. 1, row 9, second item; row 10). They deliberately and intentionally aim purely at non-truth or falsity in order to deceive others. ${ }^{50}$

49 For this last point see Notomi 1999, 153-5.

50 There is an interesting question as to how to understand Plato's characterisation of the ignorant appearance-maker who is unaware of his or her ignorance as haploun, and of the ignorant appearance-maker who is aware of his or her ignorance as eirônikon (268a7-8; see fig. 1, row 9). One possibility is that the former case involves a mental state of one single (haploun) type, whereas the latter mixes up different types of mental state: while the haplous appearance-maker (falsely) thinks he or she knows but really has just (false) doxa (268a1: oiomenos eidenai tauta ha doxazei), the eirônikos is aware that he or she only has (potentially false) beliefs/opinions or, at any rate, ignorance/lack of knowledge (268a2-3: echei pollên hupopsian kai phobon hôs agnoei 
One difficulty, however, seems to persist. How can an appearance-maker aim at falsity, deception, and illusion in a knowledgeable and so truth-entailing fashion? How can an appearance produced by this sort of appearance-maker combine in it truth stemming from knowledge, expertise, or any such factive mental state with deliberate falsity, deception, and illusion (see fig. 1, row 8, third item)? A helpful starting-point for answering these questions is to allow that an appearance may be deceiving or illusory without any unscrupulous or wicked aim. Indeed, it may have a good or at least decent goal. To set out this conceptual possibility and ground it in the text it is helpful to take up the statue example from [T4] (235e-236c). We should certainly exercise caution in considering this example as it is not exactly a mimêma in the sense of $267 \mathrm{a}-\mathrm{b}$ : for it involves external instruments such as a chisel, a rasp, a riffler, etc. It is useful, however, for our present point. When Plato introduces this example, he does not seem necessarily to categorise it as wicked, unscrupulous, or malicious. Indeed, it may be thought that the goal of aesthetic beauty is a fairly fine or noble goal - perhaps even for Plato.

It seems true, at any rate, that to produce a massive sculpture which appears to have the correct proportions by appropriately distorting these proportions is based on extensive knowledge of anatomy and physiology, of the capabilities and range of human eyesight, of optical principles of perspective, etc. The corresponding type of 'knowledgeable' appearance - for instance, a statue - would be 'true' in that it is based on such types of knowledge. Yet it would still be a product in which the original's proportions have been distorted in a deliberate but innocuous or non-malicious manner. The statue's head would be disproportionate to the feet if compared with the original's head-to-feet proportion: for the two proportions would be different. In this sense, the statue would be an inaccurate and unfaithful image. On the assumption that it is a product of successful sculpting, however, the statue would look fine and beautiful. Indeed, it would appear in this way not only despite the distortion of the original's proportions but rather because of this distortion: for its grand dimensions require this distortion for it to look proportionate (to human beholders, at least). ${ }^{51}$ In this sense, then, it would

tauta ha pros tous allous hôs eidôs eschêmatistai). So the former has just false doxa, while the latter has awareness (of his/her ignorance) plus doxa and/or ignorance. Alternatively, haplous may mean simply 'foolish' and 'sincere', and eirônikos 'suspicious' and 'insincere'. The two views are not incompatible: for one may be foolish and sincere precisely in that one possesses a unitary, single-minded state; and one may be suspicious and insincere in that one holds an intricate or complex combination of mental states. My present argument is independent of this issue.

51 Here I am in agreement with Leigh 2009, 195: '[i]n such cases, it is in virtue of the relevant visual device that the appearance appears beautiful'. 
be a truly beautiful massive statue. This type of knowledgeable appearance-making would presumably be exemplified by Da Vinci's deep knowledge of actual human anatomy but also by his expertise of appropriately distorting it to produce the desirable effects in statues, sketches, paintings, etc. His products are illusory and deceptive - they are appearances - but are underwritten by physiological, anatomical, and optical or perspectival expertise.

Are there any examples, however, of knowledgeable appearances which fall short of being 'correct' images (i.e. likenesses) but are not produced using external instruments? Such appearances would be produced by a maker's 'using himself' or 'herself', or more precisely his or her logos, presumably in the sense of rational capacity, discourse, and account. This last claim seems plausible in the light of the comparison with the demagogue and the sophist, both of whom 'use themselves' in that they use their logos in some form or other (see the occurrences of logois at 268b1-5). An example of this sort could be provided on the basis of contrasting a good, true, and correct philosophical argument with a good, truthful, and sound philosophical simile, analogy, metaphor, myth, or any similar sort of non-literal $\log o .^{52}$ Clearly, the former is based on knowledge, and so is true. But it is also a likeness, a 'correct' image, as it retains the original's proportions without any distortion. Thus, for instance, a philosophical proof from theoretical, conceptual, or even intuitive premisses and distinctions to similarly rigorous conclusions would constitute such a likeness. If the philosophical likeness-maker treats (for example) epistemological issues, his or her true likeness would consist of premisses and conclusions about knowledge, belief, or other relevant concepts. Or if the argument deals with questions about truth, truth-bearers, and truth-makers, it would derive semantic and/or metaphysical conclusions from premisses with semantic and/or metaphysical content.

A philosophical myth, by contrast, if good, truthful, and sound, typically represents and treats its subject-matter in a different or non-literal guise. Hence, for instance, while the topic is the soul's nature, immortality, and next life, the myth may present these issues figuratively using the image of a chariot and its charioteer (as Plato does in the Phaedrus) or what a soldier experienced while in (posttraumatic-stress-related?) coma (as in the Myth of Er in the Republic). Moreover, a

52 It should be emphasised that my argument does not require that knowledgeable and true philosophical analogies, similes, myths, etc. are the only types of knowledgeable and true appearances. Rather, they are important instances of such appearances. It is possible to imagine that there are (for example) knowledgeable and true rhetorical accounts which are also appearances of this sort as they refer to mythological cases, or heroic times, or remote historical events to persuade the assembly to make a correct decision, or introduce a beneficial policy, or improve existing legislation. 
sound simile, instead of spelling out its topic directly, typically compares it with something different and sets out the relevant aspects of its topic on the basis of features possessed by the similar item. Thus, the Form of the Good may be compared with the Sun; different types of mental state and their objects might be adumbrated in terms of linear segments; or intellectual progress outlined using the image of the ascent from the Cave. Here is a further example, which is closer to present concerns: while the topic is truth, how our statements and beliefs achieve it, and/or what makes them true, a knowledgeable and true appearance will employ a simile in which the soul's excellent state is compared with an archer aiming at, and hitting, the mark of truth (as in the Sophist's archery simile). In a different type of knowledgeable appearance, a good philosophical analogy will employ an item different from that under investigation, and will argue using the schema 'just as this different item, $a$, has features $F, G, H$, [...], our topic, $b$, has corresponding or analogous characteristics $X, Y, Z,[. .$.$] '. Hence, for instance, in$ the Sophist it is argued that, just as the ventriloquist Eurycles has inimical voices or spirits within him and does not need any external foes, so too the Late-Learners are self-refuted by, and within, their very own thesis, and need no external, independent argument to refute them.

It seems clear that all such cases of an appearance constitute accounts which are sound, truthful, or at least pivotal in our inquiries into truth (perhaps in that they are fundamental in philosophical education). If this is correct, they are underwritten by knowledge and so are true, even though they involve 'tweaked' or 'retuned' proportions if compared with the original. They do not accurately capture the proportions or peculiar characteristics of the relevant philosophical topic but depict these on the basis of different features of different subjects. While this implies that they are deceptive and illusory - in the manner of myths, analogies, similes, or metaphors - yet they grow out of, and contribute to, knowledge. ${ }^{53}$ If so, they are true, or at least share in truth. For example, accounts of this sort might encourage ignorant people or false opiners, such as the unexamined complacent would-be knowers treated by the elenctic purifier, to see clearly their inconsistency, falsity, give up their laziness, and so to start (re-)aiming at truth. Or it may help the merely true opiners to keep on aiming at truth and achieve a more comprehensive grasp of it, perhaps even to become knowers.

Generally, an appearance - whether knowledgeable and true or unknowledgeable and erroneous - may look like the original and so may resemble a

53 It would be the task of a separate study to examine the relation between these claims and Plato's view of truth and falsity in the central books of the Republic, as well as the implied distinction between 'good' and 'bad' types of imitation in books III and X. 
'correct' image but is not really a likeness. For a likeness aims at, and seeks to attain, truth (even though it may fail to hit the mark). An appearance, by contrast, is a product of a negative attitude to aiming at the truth. It is a sort of failure to have truth as one's target. And as all failures of this sort, it arises in numerous different ways: ${ }^{54}$ by not aiming at the truth (at all), a case which corresponds to the lazy and complacent would-be knower (see fig. 1, row 9, first item); or by aiming at non-truth or non-accuracy, that is, by seeking not to retain the original's proportions. This last case consists in aiming at falsehood, deception, and illusion, perhaps even unscrupulously so, in the manner of the demagogues and the sophists (see fig. 1, row 9, second item; row 10). But there is no reason to preclude out of hand the possibility that an appearance may be true insofar as it is knowledge-based (see fig. 1, row 8, third item). Indeed, my present argument seems to underpin this possibility by sketching a way in which such an appearance may be conceived as true.

It is worth noting that there is important evidence which suggests that the conceptions of truth given in different parts of the Sophist (apart from the 'official' account of 263b1-d5 discussed in section 2) are themselves more cognate with knowledgeable and true appearances rather than true likenesses. Thus, what I labelled the normative-teleological conception of truth relies on the archery simile. It also invokes the notion of proportion on the basis of the comparison of (possessing the) truth with (having) bodily beauty. Further, the second model of truth as proportion introduces the idea of an image's preserving or distorting the proportions of its original. This is developed in terms of the comparison with sculptors and statues. These points indicate that (part of) Plato's own philosophical account of truth in the Sophist is conceived by him as a true but (innocuously) deceptive and illusory appearance underwritten by knowledge rather than as a true likeness. ${ }^{55}$

54 This point is an allusion to Aristotle's claim made at NE. II.6, 1106b28-35, that while there is only one way in which successfully to hit the mark (of moral virtue), there are several ways in which one may fail (i.e. fall short of moral excellence). We have to be cautious, though, in our comparison of this claim with the Sophist's archery simile as I understand it. For some of the ways of missing the target of truth are in the region of likeness. Thus, for instance, a thinker who aims at truth but only manages to have true belief or (worse) false belief, falls short of absolute success: for he/she either does not achieve knowledge-based truth or altogether misses truth. More serious or worse cases of failure, however, are clearly placed within the scope of appearance. Hence, the would-be knower misses the mark as he or she does not even aim at the truth (thinking that he or she already possesses it). Moreover, the demagogue and the sophist aim at non-truth or falsity as they knowingly seek to deceive others with their falsehoods.

55 Leigh 2009, $201 \mathrm{f}$. and $204 \mathrm{f}$., offers a different account of Plato's type of argument expressed in dialogue form in the Sophist and elsewhere. While she thinks that this sort of argument is 


\section{Further Questions}

My interpretation raises at least three serious questions. In this last section I shall seek to set out these questions, and offer some tentative replies to them.

\subsection{Alêtheia: Genuineness, Reality, and Truth}

In the Sophist (but also elsewhere) ${ }^{56}$ the notion of truth (aletheia) and the true (alêthinon) are frequently used not as characterisations of standard truth-bearers, such as sentences, statements, propositions, veridical mental states, etc. Rather, they seem to coincide with the concept of reality - as, for instance, in the image of our soul's aiming at the truth - or with what is genuine, a model, or an original - as in the case of the 'true' proportions or the contrast between the 'true' and the image (236a4-6; 240a7-c3). It seems fair to compare such usages of the terms 'truth' and 'the true' with those occurring in English phrases such as 'a true friend' or perhaps even 'the truth is out there'. One may object, however, that this sense of truth cannot be used to support my interpretation, which seeks to extract quasi-semantic conceptions of truth from the relevant sections of the Sophist.

There are several different ways in which to tackle this line of objection. One may bite the bullet and argue that it is not decisive precisely because Plato's con-

an appearance, she argues that it differs not only from the sophist's appearance but also from the expert craftsman's or artist's appearance. For the latter two groups 'conceal the discrepancy between the imitative representation and the reality it represents', whereas the philosophical use of appearance in Platonic dialogues need not 'produce a piece of writing that appears to be some thing, or in some way, but is not' (204f.). Indeed, she argues, Plato's Sophist is not an instance of finalised knowledge, absolutely beyond revision, but a perspectival inquiry, one which is ineliminably dependent on the Eleatic Visitor's and, more importantly, Theaetetus' viewpoints.

56 See, for example, the simile of the Sun in Republic VI. Plato claims that the Good is the source or principle not only of knowledge and knowability but also of truth (508e10-509a5). He qualifies the way in which the Good serves this role by holding that it is responsible not only for the knowability of knowable items but also for their einai and ousia (509b5-9). Similarly, at 508d3-4, the Good provides aletheia te kai to on, where truth seems to be understood as being. Further, at 509a1-2 eyesight is analogous to knowledge, while the light is analogous to truth. But if so, truth seems to be mind-independent and external (just as the light is eye- and eyesight-independent) in the way in which being is. It seems plausible that the einai and ousia used at 509b5-9 explicate the way Plato understands 'truth'. If so, 'truth' is not an epistemic notion - truth grasped or known, or a body of propositional knowledge. Nor is it simply a property of statements, propositions, or beliefs. Rather, it seems to be 'truth' in the sense of reality, perhaps the ultimate or fundamental reality of things, for which the Form of the Good is responsible. For Plato's use of 'truth' as referring to an extra-linguistic or extra-mental item, also see Hestir 2016, 235-8. 
sidered view of truth-bearers, or at least primary truth-bearers, conceives them as external or mind-independent items. This is a form of 'ontic' or 'ontological' conception of Plato's truth, which is favoured by interpreters such as Szaif and Hestir. ${ }^{57}$ In this interpretation, what constitutes Plato's truth, or fundamental truth, is reality, but not our 'successful' statements or thoughts about reality. Further, the primary items which are true, or the items which are true in the strict or most literal sense, are not statements or mental states but extra-linguistic or mind-independent, external beings.

Alternatively, one may seek to defuse the objection by challenging the claim that 'truth' in some or all of these passages is equivalent to reality or to some notion of being genuine or being an original. Thus, for instance, it may be argued that aiming at truth need not entail (exclusively) aiming at an external reality. It may well (also) suggest that one is aiming at some propositional or mind-dependent 'body of truth', perhaps some statements or mental states of an exalted sort. This may be the way in which, for example, the noble sophistic of the $6^{\text {th }}$ definition (genei gennaia sophistikê) aims at grasping basic true propositions such as PNC (or some version of, or approximation to, that principle, along the lines of the formulation used at 230b7-8). Or the way in which dialectic studies and successfully grasps specific modes of communion (or non-communion) between certain (highest) kinds may be another way in which aiming at the truth is aiming at (fundamental) true propositions. In either case, however, the target is not any external, extra-linguistic, or mind-independent reality. Similarly, the 'true' (to alêthes) need not be any external thing but a true description of, or proposition about, such a thing included in an ideal body of knowledge, system of expertise, or fully articulated and developed science. This construal seems more congenial to approaches which emphasise the consistency requirement for truth: for our aiming at, and hitting the mark of, truth consists in some of our statements or mental states being consistent with other, perhaps more basic or important propositional items.

I think that there is a different, more promising reply, which would emphasise Plato's realistic presuppositions. In this view, Plato acknowledges that (standard) truth-bearers are linguistic or mind-dependent. At the same time, however, he seeks to highlight the realist intuition that they describe an external, mind-independent reality - the 'real thing', the genuine, original, or model. More importantly, such truth-bearers are true or false in virtue of this external reality but not conversely. Both the archery simile and the talk of original versus image suggest these realist assumptions. For the target or mark is out there independently of the

57 See Hestir 2016, 238-42; also Hestir 2003, 20-24; Szaif 1998, 72-182. 
archer, his/her aiming, and his/her success or failure. Furthermore, the original or model has causal primacy over the image: for an image is (or is not) accurate and faithful to an original in virtue of, and by reference to, the original, while the converse does not hold good.

This realist view is attractive also because it is compatible with the consistency-based idea that parts of the target 'truth' or the genuine 'true' may be propositional items. Plato's realism seems to presuppose that true statements or mental states must conform to propositions such as PNC or other important propositions about the communion of kinds. For he seems to be sympathetic to the methods of the noble sophistic, which liberates us from inconsistent beliefs as a necessary first step towards grasping further truths. Moreover, this type of Platonic realism allows even for theorising about mind-dependent or linguistic items, such as images, statements, beliefs, etc. in the way in which the Sophist offers, arguably, true (or approximately true) philosophical accounts of such items. For even items of this sort are real existents, and function as truth-makers for any philosophical theory (consisting of statements, propositions, or thoughts) putatively true of them. ${ }^{58}$

\subsection{The Charge of 'Over-Epistemicism'}

Any attempt to clarify the notion of truth should distinguish sharply between a justificatory criterion of truth and an account of what truth itself consists in. A conception of truth as such does not address the question of how we know whether, or that, $p$ is true or false. To be a proper definition of truth it should describe the nature of truth regardless of whether or how we know that truth obtains. If this is correct, there is a worry that Plato, with his emphasis on our soul, our knowledge, the rejection of false belief, etc. conflates these two separate questions. Alternatively, it may be thought that he focuses on the epistemological question, ignoring, downgrading, or discarding the semantic question.

To defuse this worry it is important to note, first, that theories of truth which emphasise the consistency requirement - most typically coherentist theories are usually inspired by, or grow out of, theories of knowledge and justification which similarly champion consistency (even though such a link is by no means necessary). ${ }^{59}$ If part of Plato's story about truth invokes consistency, as his

58 Hestir 2016, 240, argues that statements, too, are beings of some sort, parts of the fabric of the real world, even though they are not extra-linguistic or mind-independent.

59 See Haack 1978, 91; Walker 1989, 5-9; 167 f. 
remarks in the 6th definition indicate, it seems unsurprising that he proceeds from epistemological considerations.

There is a second, more important point. Plato's references to knowledge, belief, or other epistemic states are not indispensable. They are not fully set out or heavily relied upon in his account of truth. There is, to be sure, an important discussion of the noblest scientific discipline, dialectic. Further, Plato seems to be describing (part of) the subject-matter of that science in his treatment of the communion of kinds. Beyond these points, however, he does not analyse knowledge or belief in any considerable depth. Nor does he invoke any fine-grained distinctions between different types of mental state or deal with any themes of justification, explanation, grasp of causation, etc. The notion of logos is used cognately with such epistemic concerns only in the discussion of dialectic, a specific - presumably the paradigmatic - scientific field (253b9-c3; 254a8-b1; 260a5-b2). But logos does not seem to have any similar connotations in Plato's official or more figurative points about the nature of truth. ${ }^{60}$

Moreover, it seems unwarranted to assume that a conception of the nature of truth ought not to invoke mental states such as knowing or opining. For it is incontrovertible that such mental states are amongst the most significant truth-bearers. Apart from sentences, statements, and propositions, beliefs, pieces of knowledge, opinions, etc. are true or false. ${ }^{61}$ In a slightly different formulation of this same point, certain mental states are essentially related to truth-bearers such as (for instance) propositions: $A$ believes that $p$; $B$ knows that $q$; $C$ opines that $r$; etc. Indeed, Plato's strategy in the Sophist suggests precisely this point: first, he introduces an account of negation and not-being, followed by an account of statements, then he sets out true and false statements, and finally asks whether and how (true or) false statements 'mix with' thought or belief (263d6-8; e3-5; 264a8-b4). This is a picture of mental states relating to propositional items, some of which are factively true (as in the case of known propositions), some either true or false (what doxa ranges over), others erroneous or just false (items related to

60 Moreover, while Plato distinguishes originals from images, and divides the latter into likenesses and appearances, he does not raise or address in any depth the epistemological questions of how one can (knowledgeably) recognise an image as just an image, how one can recognise an image as an image of a specific original, or how one can even recollect (in the technical sense) a Form on the basis of some of its perceptible images (or manifestations). Nor does he discuss the related cases of epistemic failure: how one can mistake an image for an original, or vice-versa, and how one can mistake a likeness for an appearance, or vice-versa. Some of these important epistemological questions about recognition and recollection are raised by Harte 2006, 21-42.

61 Compare how Aristotle straightforwardly categorises beliefs or similar mental states together with other typical truth-bearers: Metaph. E.4, 1027b25-28; 29-33; Ө.10, 1051b3-5; 6-9; 13-15. 
unknowledgeable appearances). If this is correct, Plato's primary interest seems to be not in epistemology but in the nature of truth and falsity.

\section{3 'Semanticalism', Consistency, Correspondence, or Pictorialism?}

Perhaps the most urgent question arising from Plato's discussion of truth in the Sophist is whether he has a unified view of truth or whether he is ambivalent, confused, or even inconsistent. His 'official' account - what I labelled 'semanticalism' in section 2 - points to Tarskian ideas. While some interpreters have argued that this account is a version of the correspondence theory of truth, I agree with Hestir that this characterisation seems incorrect in the sense of modern correspondence theories. ${ }^{62}$ The archery simile and the related normative-teleological conception imply a consistency-oriented theory of truth but also allow for (or do not rule out) further ideas of aiming at an external, mind-independent 'truth' or reality. Finally, the image-based conception, with its reliance on the distinction between original and copy, could suggest either a correspondence view (perhaps in the manner of Russell) or a 'picture' theory of truth (along the lines of the early Wittgenstein). ${ }^{63}$

Does this plethora of conceptions indicate that Plato has more than one account of truth or simply that he has no single coherent view? This is a difficult question. An attractive idea might be that these distinct and independent conceptions are mutually complementary and unified. Thus, the 'official' account describes what a true (or false) statement consists in, or what it does, on the basis of its being of/about a thing, and saying (or failing to say) that what is (of/about that thing) is. The ideas underlying the archery simile and the normative-teleological view might be making either or both of the following two points. They may be explicating certain necessary conditions for a statement or belief to be true: its compliance with PNC, its conformity to the communion relations holding between kinds, etc. Or they may be pointing out that by nature a true or false statement or belief interacts, or is intimately linked, with other statements or beliefs. If so, these ideas follow a more holistic approach to truth and spell out consistency-based necessary conditions for a system of propositions or beliefs to be true: again such a system ought to be regulated by (for example) PNC and the correct communion relations between kinds. The original-image conception

62 See Hestir 2016, 183-233; see also Hestir 2003, 13 f.

63 For this sort of comparison with Wittgenstein, see Tilghman 1969, 160. 
underwrites further the 'official' account by specifying in virtue of what a true (or false) statement is of/about something and says (or fails to say) that what is (of/ about that thing) indeed is. ${ }^{64} \mathrm{~A}$ statement achieves (or falls short of) these twin goals in virtue of being a certain type of image (correct or incorrect; factively true; true or false; deceitful; etc.) which has been made (by a relevant image-producer) similar to an original or model, a genuine (part of) reality external to this image.

It should be noted that this is a bona fide account of the nature of truth and of the relevant truth-bearers. It describes an intrinsic feature of truth-bearers in virtue of which they are either true or false - their being images of some sort produced by thought and/or language. But it also points to a realist view of truth-makers as it invokes the notions of an original and of external reality. The latter make images true, or they make them false. Put differently, images are true or are false, as the case may be, in virtue of their originals but not conversely. It is certainly the case that human thought and language produce images but, in so doing, they produce items which are either true or false. They do not make any given image true, nor do they make it false, as the case may be. In Plato's view, this fundamental role is served by the relevant original, the external, mind-independent reality an image is an image of. If all these considerations are correct, the plural 'conceptions' in the title of the present study may be misleading: for Plato's account of truth in the Sophist may be multifaceted, complex, and tiered but proves fundamentally unified..$^{65}$

64 While Hestir's approach is different from mine, this point shows (I think) that we agree that Plato's language of original and image does not require either a congruence or a correlation variant of the correspondence theory of truth (Hestir 2016, 212-9). Nor, I submit, does it require a 'pictorialist' theory of truth. My present claim is just that the original-image talk highlights Plato's interest in truth-makers and their asymmetry over truth-bearers (statements, mental states, etc.): for the former constitute that in virtue of which the latter are true, or are false, while the converse is not the case. It is important to emphasise that, in my interpretation of Plato's view, this asymmetry does not define his conception of truth, nor is it a part of the nature of truth. Rather, my claim is simply that, in Plato's conception, truth depends on truth-makers and their asymmetry over truth-bearers.

65 I am indebted to Lesley Brown, Guus Eelink, Gail Fine, Mark Gatten, and Blake Hestir, who read earlier versions of this paper and made extensive and invaluable comments on it. An earlier version of the paper was presented at the Oxford Ancient Philosophy Workshop and at Noburu Notomi's and Satsuki Tasaka's seminar in Risho University, Tokyo. I am indebted to all the participants for their helpful comments. The same version was also discussed at the Worcester Work in Progress Seminar, where Andrea Christofidou, Sabina Lovibond, Steven Methven, and Stephen Williams made extremely helpful comments and criticisms. Finally, I thank the two anonymous referees of the Archiv for their comments and criticisms. I am solely responsible for any remaining mistakes. 


\section{Conceptions of Truth in Plato's Sophist}

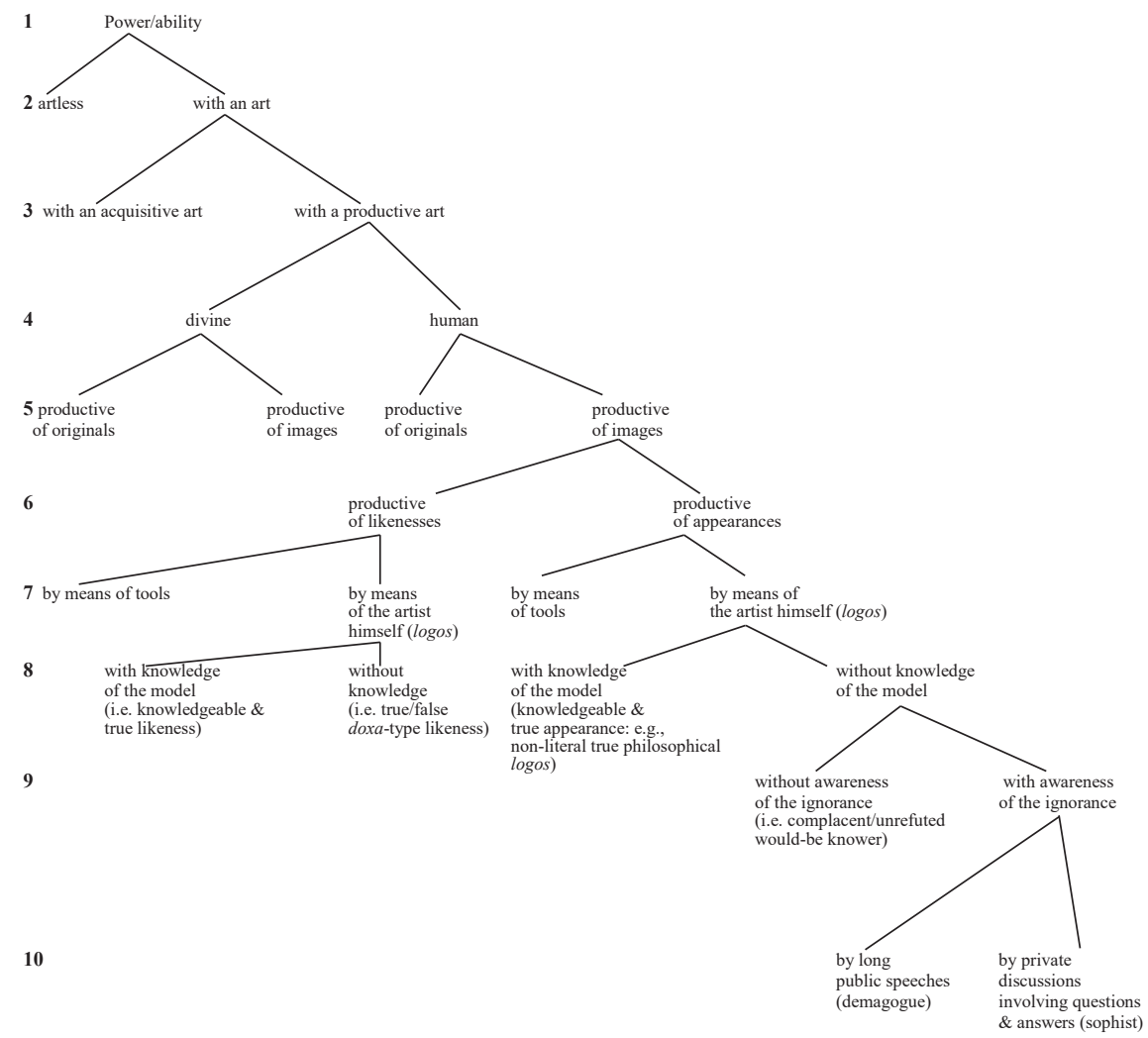

Figure 1: Plato's Sophist: the $7^{\text {th }}$ Definition of the Sophist

Bluck, R. S. 1975. Plato's Sophist: A Commentary. Manchester.

Bondenson, W. 1972. "Plato's Sophist: Falsehoods and Images". Apeiron 6, 1-6.

Bostock, D. 1984. "Plato on 'Is-Not' (Sophist 254-9)". Oxford Studies in Ancient Philosophy II, 89-119.

Brown, L. 2010. “Definition and Division in Plato’s Sophist”. In Definition in Greek Philosophy.

Ed. D. Charles. Oxford, 151-171.

Crivelli, P. 2012. Plato's Account of Falsehood: A Study of the Sophist. Cambridge.

Frede, M. 1992a. “Plato's Sophist on False Statements”. In The Cambridge Companion to Plato. Ed. R. Kraut. Cambridge, 397-424.

-. 1992b. "Plato's Arguments and the Dialogue Form". Oxford Studies in Ancient Philosophy. Supplementary volume. Oxford, 201-19.

Gill, M. L. 2012. Philosophos: Plato's Missing Dialogue. Oxford.

Gulley, N. 1962. Plato's Theory of Knowledge. London. 
Haack, S. 1978. Philosophy of Logics. Cambridge.

Harte, V. 2006. "Beware of Imitations: Image Recognition in Plato". In New Essays on Plato: Language and Thought in Fourth-Century Greek Philosophy. Ed. F.-G. Hermann. Swansea, 21-42.

Hestir, B. E. 2016. Plato on the Metaphysical Foundation of Meaning and Truth. Cambridge. Hestir, B. E. 2003. “A ‘Conception' of Truth in Plato's Sophist”. Journal of the History of Philosophy 41, 1-24.

Keyt D. 1973. "Plato on Falsity: Sophist 263B". In Exegesis and Argument: Studies in Greek Philosophy Presented to Gregory Vlastos. Eds. E. N. Lee/A. P. D. Mourelatos/R. M. Rorty. Assen, 285-305.

Leigh, F. 2009, “Plato on Art, Perspective, and Beauty in the Sophist". Literature and Aesthetics 19, 183-214.

Notomi, N. 1999. The Unity of Plato's 'Sophist': Between the Sophist and the Philosopher. Cambridge.

Rosen, S. 1983. Plato's Sophist: The Drama of Original and Image. New Haven.

Szaif, J. ${ }^{21998 . ~ P l a t o n s ~ B e g r i f f ~ d e r ~ W a h r h e i t . ~ M u n i c h . ~}$

Tarski, A. 1944. "The Semantic Conception of Truth and the Foundations of Semantics". Philosophy and Phenomenological Research 4, 341-76.

Tilghman, B. R. 1969. “Parmenides, Plato, and Logical Atomism”. Southern Association of Philosophy 7, 151-160.

Walker, R. C. S. 1989. The Coherence Theory of Truth: Realism, Anti-Realism, Idealism. London/ New York. 